.

2

3

\title{
A Multi-sensor Study of the Impact of Ground-based Glaciogenic Seeding on Clouds and Precipitation over Mountains in Wyoming. Part II: Seeding Impact Analysis
}

(1)

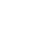

$$
\text { Binod Pokharel }{ }^{\mathrm{a} *} \text {, Bart Geerts }{ }^{\mathrm{a}}, \text { Xiaoqin Jing }{ }^{\mathrm{a}} \text {, Katja Friedrich }{ }^{\mathrm{b}}, \text { Kyoko Ikeda }^{\mathrm{c}} \text {, and Roy }
$$

Rasmussen $^{\mathrm{c}}$

${ }^{a}$ Department of Atmospheric Science, University of Wyoming, Laramie, Wyoming 82071, USA

${ }^{\mathrm{b}}$ Department of Atmospheric and Oceanic Sciences, University of Colorado, Boulder, Colorado 80309, USA

${ }^{\mathrm{c}}$ Research Application Laboratory, National Center for Atmospheric Research, Boulder, Colorado 80307, USA

4

${ }^{*}$ Corresponding author: Binod Pokharel, Dept. of Atmospheric Science, University of Wyoming, Laramie, WY 82072 USA. Email: bpokhare@uwyo.edu 


\section{Abstract}

The AgI Seeding Cloud Impact Investigation (ASCII) campaign, conducted in early 2012 and 2013 over two mountain ranges in southern Wyoming, was designed to examine the impact

21 of ground-based glaciogenic seeding on snow growth in winter orographic clouds. Part I of this 22 study (Pokharel and Geerts, 2016) describes the project design, instrumentation, as well as the 23 ambient atmospheric conditions and macrophysical and microphysical properties of the clouds 24 sampled in ASCII. This paper (Part II) explores how the silver iodide (AgI) seeding affects snow 25 growth in these orographic clouds in up to 27 Intensive Operations Periods (IOPs), depending on 26 the instrument used.

In most cases, two hours without seeding (NOSEED) were followed by two hours of seeding (SEED). In situ data at flight level (2D-probes) indicate higher concentrations of small 29 snow particles during SEED in convective clouds. The double difference of radar reflectivity $Z$ (SEED - NOSEED in the target region, compared to the same trend in the control region)

31 indicates an increase in $Z$ for the composite of ASCII cases, over either mountain range, and for 32 any of the three radar systems (WCR, MRR, and DOW), each with their own control and target 33 regions, and for an array of snow gauges. But this double difference varies significantly from 34 case to case, which is attributed to uncertainties related to sampling representativeness and to 35 differences in natural trends between control and target regions. We conclude that a sample 36 much larger than ASCII's sample is needed for clear observational evidence regarding the 37 sensitivity of seeding efficacy to atmospheric and cloud conditions. 


\section{Keywords:}

40 Glaciogenic seeding; orographic cloud and precipitation; radar reflectivity; airborne

41 measurements

42 Abbreviations:

43 ZIP, reflectivity impact factor; PIF, precipitation impact factor; ASCII, AgI Seeding Cloud

44 Impact Investigation; UWKA, University of Wyoming King Air; WCR, Wyoming Cloud Radar;

45 WCL, Wyoming Cloud Lidar; MRR, Micro-Rain Radar; DOW, Doppler on Wheels 


\section{Introduction}

This is the second part of an observational study that explores whether a measurable signal of ground-based glaciogenic seeding can be detected, in terms of ice crystal size distribution and mainly snowfall rate. Pokharel and Geerts (2016, hereafter referred to as Part I) describes the AgI Seeding Cloud Impact Investigation (ASCII) experimental design, as well as the characteristics of the sampled orographic clouds, flow field, and upstream stability profiles in ASCII's 27 intensive operation periods (IOPs). A map of the terrain, the facilities deployed in ASCII, and the flight track of the University of Wyoming King Air (UWKA) is shown in Fig. 1.

54 This paper (Part II) compares particle size distributions, precipitation rates, and mainly radar 55 reflectivity profiles for all these IOPs. Comparison are drawn both spatially (target vs. control 56 regions) and temporally (SEED vs. NOSEED). Comparisons using three different radar systems are described in Section 2, and estimated in Section 4, using double differences based on these radar systems as well as snow gauges. Caveats and suggestions for improvements are discussed in Section 5. The findings are

61 summarized in Section 6.

\section{Change in radar reflectivity}

This section examines the change in reflectivity from NOSEED to SEED periods for three different radar systems, each with their own target and control regions. These are the Wband (3 mm) airborne profiling Wyoming Cloud Radar (WCR), the volume-scanning X-band (3 $\mathrm{cm})$ Doppler on Wheels (DOW) radar, and a pair of profiling Ka-band $(1.2 \mathrm{~cm})$ Micro Rain 
WCR, based on all available ASCII IOPs, listed in Table 1 in Part I. First we define the control region as the flight leg upwind of the AgI generators (leg 1 in Fig. 1) and the target region as the four downstream legs (Section 2.1). Next, to build evidence that differences are seeding-related, we contrast temporal changes inside dispersion plumes (target) against those outside (control) (Section 2.2). We also contrast Medicine Bow (MB) vs. Sierra Madre (SM) (Section 2.3), and convective vs. stratiform clouds (Section 2.4). Finally, we evaluate the reflectivity changes from NOSEED to SEED for the MRR pair (Section 2.5) and for the DOW (Section 2.6).

\subsection{Target and control WCR reflectivity}

A seeding signature is not immediately obvious in the reflectivity pattern downwind of AgI generators in any IOP. Therefore the WCR reflectivity profiles are composited for all flight legs in the form of frequency-by-altitude displays (FADs) (Yuter and Houze, 1995). The frequency is normalized, such that any number of transects can be added, and the sum of all counts (all heights, all reflectivity bins) equals $100 \%$. The height is expressed above ground level (AGL) because AgI seeding is ground-based and, to a first order, low-level tracers are advected over the terrain, roughly following the terrain contour. The FAD approach has been used in several ASCII case studies (Pokharel et al., 2014a, b; Pokharel et al., 2015). Here we use it for the composite of all available cases: the WCR reflectivity FAD for 21 ASCII IOPs is shown in Fig. 2. This includes nine IOPs over the SM and 12 IOPs over the MB. Three IOPs in pre-ASCII (10, 25 and 30 March 2009) are excluded because no control measurements were collected (Table 1 in Part I).

WCR reflectivity data from the target tracks (legs 2-5) and the control track (leg 1) are composited during NOSEED and SEED (Fig. 2). In most IOPs NOSEED preceded SEED, 
92 enabling a rapid transition between the two periods, although the UWKA flew one or two cross-

93 mountain along-wind legs between the two periods (e.g., Fig. 4 in Part I), to allow AgI nuclei to

94 disperse. Both periods usually contain two full ladders of five legs (Fig. 1), and thus the WCR

95 sample size of SEED is about the same as that of NOSEED. As can be seen in the cumulative

96 distance listed in upper four panels of Fig. 2, the SEED sample size is $15-20 \%$ smaller on

97 average than the NOSEED sample size in both regions. This is because in some IOPs the aircraft

was unable to complete the $4^{\text {th }}$ ladder (part of SEED), and in some cases the wind was not strong

enough for the first leg flown on ladder 3 (leg 5, furthest downwind, Fig. 1) to be counted as part

100

101

102

103

104

105

106

107

108

109

110

111

112

113

114

of SEED. The exact start and end times for NOSEED and SEED are listed in Table 1 in Part I.

The dip in the "data presence" line between 1-2 km AGL in all upper four panels in Fig.

2 is an artifact due to the radar blind zone (e.g., Fig. 4 in Part I). It gives an indication of the typical flight level AGL. The average reflectivity is computed in $Z$ units $\left(\mathrm{mm}^{6} \mathrm{~m}^{-3}\right)$ and

expressed in dBZ in Fig. 2. It is converted to precipitation rate $R\left(\mathrm{~mm} \mathrm{~h}^{-1}\right)$ in the upper abscissa of the two lower panels of Fig. 2 using:

$$
\mathrm{R}=\mathrm{aZ}
$$

For the WCR we use $a=0.39$, and $b=0.58$ in eqn (1), based on Pokharel and Vali (2011), who use WCR data collected over and near the MB range. This is close to the Z-R relationship derived theoretically for mm-wavelength radar by Matrosov (2007). The uncertainty in these relationships is large (larger than factor of two), mainly because of the uncertainty in ice particle density, which is strongly affected by riming. For the MRR and the DOW radars, we use $a=0.046$, and $b=0.67$ in eqn (1), based on Matrosov et al. (2009). The precipitation rate in Fig. 2 is a conditional rate, i.e. when it is snowing. The fraction of time it was snowing at any height can be estimated from the data presence line. 
The data presence is suppressed near the surface in the control region (foothills),

compared to the target region (over the mountain), where significant reflectivity values $(>0 \mathrm{dBZ})$ near the surface are far more common (Fig. 2a and d). Also, the average low level reflectivity is 1-2 dBZ smaller in the control region compared to the target region during NOSEED. These are orographic effects, i.e. snow grows at low levels above the LCL (Table 1 in Part I) over the mountain. Echoes are often elevated (not reaching the ground) along leg 1, as can be seen on the west side of the transects in Figs. 4 and 5 in Part I. Fig. 2 also confirms that storms sampled in ASCII were quite shallow, with echoes present at $4 \mathrm{~km}$ AGL less than $20 \%$ of the time on average.

We now compare two periods, SEED vs. NOSEED, for the composite of 21 IOPs. The average low-level reflectivity remains the same from NOSEED to SEED in the control region (Fig. 2c), but it increases in the target regions from NOSEED to SEED (Fig. 2f): in the lowest $1.5 \mathrm{~km}$ the average reflectivity is $\sim 1.5 \mathrm{dBZ}$ larger during SEED, which corresponds with a $\sim 30 \%$ increase of the precipitation rate, according to eqn (1). This increase is largely due to an increased frequency of strong ( $>10 \mathrm{dBZ}$ ) echoes at low levels during SEED in the target region. This increase cannot be attributed to storm deepening during SEED: the upper-level (>2 $\mathrm{km}$ AGL) mean reflectivity and data presence in fact is generally lower during SEED in the target region (Fig. 2). The same weakening aloft, from NOSEED to SEED, is found in the control region: the structure of the two difference FADs in Fig. $2 \mathrm{c}$ and $\mathrm{f}$ is similar (i.e. the redblue-red sequence at upper levels), indicating that the natural storm trend above the seeded boundary-layer was similar in target and control regions. In some IOPs the storm weakened, in other cases reflectivity above the PBL tended to increase from NOSEED to SEED periods. The net effect for 21 IOPs is a slight weakening aloft. 
2.2 WCR reflectivity: comparison with a lateral control region

To further explore the possibility that the low-level change in WCR reflectivity is due to

AgI seeding, we contrast changes in the sections of flight legs assumed to be within an AgI

142 plume downwind of a generator, against section believed to be outside any plume. We do this

143 mainly because lateral control, over similar terrain, is more representative than upwind control,

144 over the foothills: for instance, an increase in stability and/or decrease in wind speed tends to

145 shift orographic precipitation upwind of the mountain (e.g., Houze, 2012). Also, the upwind

146 control region is rather small (1 flight leg) compared to the target region (4 legs). The drawback

147 of the lateral control approach is that the AgI dispersion plumes were not measured

148 independently (e.g. by releasing an inert tracer from the AgI generator sites, and measuring its

149 concentration downwind). There is some evidence that AgI seeding plumes tend to be rather

150 narrow, both from observations (Holroyd et al., 1988; Huggins, 2007) and from modeling work

151 (Xue et al., 2014). We can be fairly confident that under the rather low-stability, high-wind

152 conditions observed in ASCII (see Part I), the AgI dispersion plumes are almost always

153 contained within a cone confined by $\pm 10^{\circ}$ of the mean low-level wind direction from the left-

154 and right-most generators. The flight sections within this box ("target") are shown in the insert

155 map in Fig. 3a. The flight sections outside this box ("lateral control") are shown in the insert

156 map in Fig. 3b. Only the 20 IOPs with two or three AgI generators in operation are used for this

157 analysis (Table 1 in Part I). This approach allows a more balanced sampling in the target region 158 (51\% of the composite flight track length) vs. the lateral control region (49\%) during SEED and

159 NOSEED. There is a chance of course that the lateral control region occasionally is impacted by 160 seeding especially for low Froude number or high wind shear cases. 
A higher frequency of enhanced reflectivity during SEED is observed both inside the

162

163

164

165

166

167

168

169

170

171

172

173

174

175

176

177

178

179

180

181

182

183

target cone and the lateral control region (Fig. 3). But this increase in reflectivity is mainly aloft

in the lateral control region, and mainly below $1 \mathrm{~km}$ within the target cone. The near-surface

dipole of increased chances of high reflectivity values $(\sim 11 \mathrm{dBZ})$ and decreased chances of

slightly lower reflectivity values ( 6 dBZ) within the target cone is striking (Fig. 3a). This

suggests that the observed low-level reflectivity increase in the target region, compared to the

corresponding change in the upwind control region (Fig. 2c and f), arises mostly from changes

immediately downwind of the AgI generators. It is one piece of evidence suggesting that ground-

based seeding increases radar reflectivity. This piece of evidence will become clearer in Section

4, where we introduce a double ratio.

\subsection{WCR reflectivity: Medicine Bow versus Sierra Madre}

The orographic clouds sampled over the MB were $\sim 5 \mathrm{~K}$ colder than those over the SM

(Fig. 3 in Part I). Do the findings from the composite analysis (Fig. 2) apply to both mountains individually? The WCR reflectivity is higher during SEED compared to NOSEED both in the (upwind) control and target regions over the MB (Fig. 4a and b), suggesting storm intensification from NOSEED to SEED. However, the opposite applies for the SM cases: the reflectivity is lower during SEED in both regions (Fig. 4c and d), suggesting storm decay. Natural trends vary widely from one IOP to another. But the SEED-NOSEED increase (decrease) in low-level reflectivity in the target region compared to the control region is larger (smaller) over the $\mathrm{MB}$ (SM). If we consider the change in the control region as natural variability, and the change in target region is natural variability plus seeding impact, then the WCR reflectivity data suggest a positive seeding impact over both mountains. 
2.4 WCR reflectivity: convective versus stratiform clouds

The impact of ground-based seeding on snow growth may depend on cloud type. The AgI

187 nuclei are mixed only within the turbulent PBL in stratiform cases, while convection may carry

188 seeding material to higher levels. To analyze the effect of cloud type, the 21 IOPs used for Fig. 2

189 are grouped into convective and stratiform types of cloud (Table 1 and Section 3.3, both in Part

190 I). Six of these 21 IOPs are classified as convective, and the remaining 15 are stratiform. The

191 (upwind) control (leg 1) and target (legs 2-5) regions are the same for all cases.

192

The target region shows enhanced low-level reflectivity during SEED for both cloud

types (Fig. 5a and c), with a higher probability of strong (>10 dBZ) echoes near the surface,

194 especially for stratiform clouds. The corresponding trend in the control region is rather insignificant for both cloud types (Fig. $5 b$ and d), with a slight weakening in convective cases.

196 (The spike at $1.5 \mathrm{~km}$ AGL in Fig. $5 \mathrm{~b}$ is an artifact due to the radar blind zone, resulting in very 197 few data near that level.) The low-level reflectivity difference (SEED - NOSEED) in the target 198 region, compared to the corresponding difference in the control region, is about the same for 199 both cloud types: this double difference (introduced in Section 4 below) is $1.4 \mathrm{~dB}$ when averaged 200 over the lowest $1 \mathrm{~km}$ AGL. This WCR-based finding is consistent with a DOW analysis of fewer 201 ASCII cases for stratiform (Jing et al., 2015) and convective (Jing and Geerts, 2015) clouds. It is 202 possible that a larger positive response would emerge from the convective cases, if the target 203 region were to extend further in the lee than leg 5 (Fig. 1), since most precipitation in these cases 204 fell in the lee (Section 4.2 in Part I). 
Two MRRs were deployed in ASCII-12, one upstream of the AgI generators, and one downstream, at Battle Town site in the SM (Fig. 1). MRR reflectivity profiles at Battle Town site can be used to analyze seeding impact only if the site is impacted by the AgI plume.

Evidence for this impact comes from two methods, (1) wind direction and (2) concentration of silver $(\mathrm{Ag})$ and other trace elements in freshly fallen snow samples at Battle Town site. The predicted plume advection pattern is based on the average wind direction between the surface and mountain top level, using one or more upwind soundings during SEED. The minimum distance between the plume's center and Battle Town site is calculated, for any active AgI generator. The smaller this distance, the more likely it is that snow grown between the source and Battle Town site is impacted by AgI. The Ag concentration in the snow samples collected SEED (relative to the NOSEED baseline concentration) is compared with the minimum distance to the closest plume center (Fig. 6).

The Ag concentration increase in snow samples collected during SEED is insignificant or negative when the minimum distance is large ( $>4 \mathrm{~km}$ ). All but two cases (February 10 and 21) do show a more-than-doubling of the Ag concentration during SEED when the minimum distance is small $(<4 \mathrm{~km})$. There are many possible reasons for the two exceptions, but we can only speculate. Certainly the number of snow samples during SEED was small in both cases, as the snowfall rate was light. This confirms that when the predicted AgI plume is not far from Battle Town site, the snow sample reveals a higher Ag concentration during SEED.

The analysis in Fig. 6 yields eight IOPs (out of 12) suitable for the seeding impact analysis of data collected at Battle Town site, i.e. those IOPs with a minimum distance $<4 \mathrm{~km}$. The two IOPs for which the Ag concentration does not more-than-double are included as well, essentially because we have little faith in the Ag measurements in these two cases. The eight 
230 IOPs are listed in Table 1. The first two cases in this table (January 18 and 19) do not have data 231 for the upstream MRR, so only six cases are considered for the dual-MRR analysis. The MRR data are reprocessed to reduce noise, following Maahn and Kollias (2012).

233 Except during heavy snowfall, the first two range gates had to be discarded, thus the effective 234 minimum data level for the reflectivity FAD is $450 \mathrm{~m}$ AGL for the MRR at Battle Town site, 235 and $700 \mathrm{~m}$ for the upwind valley MRR, whose gate spacing was larger. The MRRs are less 236 sensitive than the WCR (minimum detectable echo at a range of $1 \mathrm{~km}$ is $\sim-8 \mathrm{dBZ}$ for the MRR, 237 vs - $25 \mathrm{dBZ}$ for the WCR), but the larger particles scatter more strongly, because the size boundary between Mie and Rayleigh scattering is four times larger. Thus for heavy snowfall any Z-R relationship applies better at Ka-band (and a fortiori at X-band) than at W-band.

The SEED minus NOSEED reflectivity FADs composited for these six IOPs are shown in Fig. 7 for the downstream MRR (top panel) and the upstream MRR (bottom panel). The mean

242 vertical reflectivity gradient at the downstream site (solid or dashed lines in Fig. 7a) is rather 243 high, due to subsidence aloft and low-level snow growth below. This gradient is smaller at the 244 upstream site (Fig. 7b), as echoes tend to be deeper at the upstream site (the foothills region), 245 and in fact low-level sublimation may occur, producing an elevated $Z$ maximum. [See Figs. 4 246 and 5 in Part I for examples, and Geerts et al. (2015a) for a detailed discussion of this orographic 247 effect.]

The NOSEED and SEED periods for the MRR analysis (Table 1) are slightly different

249 from those for the WCR (Table 1 in Part I). For all IOPs, NOSEED is defined as an equally long 250 period as SEED, which is the actual seeding period adjusted for the typical advection time 251 between the AgI source and Battle Town site. The target MRR did not work for $\sim 30$ minutes 252 during SEED in one IOP (21 February 2012), so the MRR's SEED sample size is slightly 
253

254

255

256

257

258

259

260

261

262

263

264

265

266

267

268

269

270

271

272

273

274

275

smaller than the NOSEED sample size (Fig. 7). The upstream MRR composite reflectivity FAD shows that, on average, storms were weakening between NOSEED and SEED, both aloft and at low levels (Fig. 7b). The same weakening is evident above the PBL at the target site impacted by AgI seeding (Fig. 7a), except in the lowest $0.8 \mathrm{~km}$ AGL.

If the MRR NOSEED period is defined as a longer, two-part period straddling the (typically two-hour long) SEED period, with a one-hour buffer period after SEED, then the sixstorm composite SEED-NOSEED reflectivity difference FAD still shows a somewhat lesser storm intensity during SEED at the upstream control site, while the difference FAD at the target site still reveals a higher mean reflectivity at low levels during SEED (not shown), consistent with Fig. 7.

\subsection{Target and control DOW reflectivity}

A DOW radar located at Battle Pass (Fig. 1) conducted volume scans at 10 min intervals during the ASCII-12 IOPs. Battle Pass affords excellent low-level coverage to the W and E-NE, but higher terrain along the crest to the NW and especially to the SE results in poor low-level coverage in those sectors (Fig. 8a). Two control areas can be used for the DOW. An upwind control region is intended to capture precipitation areas moving towards Battle Pass. It is defined as an area generally upwind of the AgI generators with lowest-elevation DOW data no more than 1.0 km AGL (Fig. 8a). When only the three core AgI generators were used, the upwind control region was confined on the sides by the wind direction, as shown in by black lines in Fig. 8b, and as described in more detail in Jing et al. (2015). The lateral control region, designed to represent conditions over the mountain, but to the side of the AgI plumes, is outside these black lines, in an area over the mountain with reasonable low-level coverage (lowest beam $<1 \mathrm{~km}$ AGL). Lateral 
276 control applies only to IOPs with just three generators. Finally, the target is a region downwind

277 of the AgI generators, stretching 18 km downwind of Battle Pass (Fig. 8a). The DOW's low-

278 level coverage is excellent in the target region. The processing of the DOW data and the start and

279 end times of NOSEED and SEED for all IOPs are described in Jing et al. (2015) and Jing and

280 Geerts (2015). The DOW SEED and NOSEED periods are similar to those for the MRR and the

281 gauges (Table 1), with adjustment for advection given the rather large target region.

282

Of the 12 IOPs over the SM (Table 1 in Part I), 10 were found to be suitable for DOW-

283 based seeding impact analysis (Table 1). The two others (18-Jan and 14-Feb 2012) show no

284 measurable echoes in the upwind control area during at least one of the periods (SEED or

285 NOSEED), such that double differences cannot be calculated. Of the 10 good IOPs, three had

286 convective echoes and seven had stratiform echoes only. All generators were used in three IOPs

287 (Fig. 8a), and just the core generators (Fig. 8b) were used in the other seven (Table 1 in Part I).

288 The wind direction was not suitable for a lateral control region to be defined in two of these 289 seven IOPs, leaving just five IOPs.

290 The DOW reflectivity difference FADs (SEED-NOSEED) are shown separately for the

291 two control regions and the target region in Fig. 8c-e. Storms generally show a trend towards

292 stronger echoes during SEED. Below $1 \mathrm{~km}$ AGL, there is no net change (mean reflectivity values

293 match) in both control regions, but not in the target region. In fact the blue-red dipole, with

294 higher (lower) chances of high reflectivity values during SEED (NOSEED), is strongest in the 295 lowest $1 \mathrm{~km}$ in the target region.

296

297 3. Change in ice particle concentration

$298 \quad 3.1 \quad$ Ice particle concentrations at the surface 
As discussed in Section 2.5, the AgI plume likely reached the Battle Town site in eight

300

301

302

303

304

305

306

307

308

309

310

311

312

313

314

IOPs in ASCII-12. Data from a Parsivel disdrometer at this site for these eight IOPs is partitioned into two periods (NOSEED and SEED, Table 1). The resulting ice particle size distribution data are composited in frequency-by-diameter-displays (FDDs) (Fig. 9). An FDD shows the normalized probability of a concentration of particles within a certain size bin. The mean particle concentration (solid line in Fig. 9a or b) tends to drop off exponentially with size, as expected. A bimodal distribution is apparent, with a secondary peak of small-particle concentrations an order of magnitude larger than the main peak, during SEED and especially during NOSEED. An FDD difference plot (Fig. 9c) shows a lower concentration of particles of all sizes (larger than $\sim 300 \mu \mathrm{m}$ ) during SEED. This implies a lower reflectivity during SEED. This is not consistent with the FAD of the Battle Town site MRR (Fig. 7a), which shows a slightly higher reflectivity during SEED at the lowest level. But the MRR composite only spans six IOPs (Table 1). In both missing IOPs (18 and 19 January) the Parsivel concentration of especially larger ice particles is lower during SEED than NOSEED. Yet because the snowfall is light and shallow in both of these IOPs, the exclusion of these two IOPs (not shown) does not make the Parsivel SEED-NOSEED comparison consistent in sign with the MRR comparison at Battle Town site (Fig. 7a).

The sensitivity of the results can be quite sensitive to the number of IOPs available, especially when no control data are available. An example is the 28a-Feb IOP (Table 1), which experienced a deep cloud ( 5-6 km deep) with intense snowfall during NOSEED, and then clouds only half as deep with lighter snowfall and almost no large aggregates during SEED. Exclusion of this IOP (not shown) yields a more positive SEED-NOSEED difference for both Parsivel and target MRR. Ideally a second "control" Parsivel would have operated 
322 simultaneously on the mountain crest, but away from the AgI plumes. As discussed in Part I

323 (Section 3.1), all available IOPs (except two, with changes in weather conditions during the IOP)

324 are included. The number of IOPs differs from probe to probe, depending on data availability

325 and evidence for suitable wind (Section 2.5).

326

$327 \quad 3.2 \quad$ Ice particle concentrations at flight level

Flight-level data generally are not useful to examine the impact of ground-based seeding,

329 since the typical flight level was $610 \mathrm{~m}$ above the highest terrain in the SM and the MB. (This is

330 the lowest permissible flight level in cloud.) But since convective clouds carry PBL air towards

331 cloud top, the probability is higher that the AgI-impacted snow reaches flight level in convective

332 clouds. Also, compared to the disdrometer on the ground, flight-level ice particle concentrations

333 are not contaminated by blowing snow, and the smallest particle size measurable by a Cloud

334 Imaging Probe (CIP) is about one order of magnitude smaller than for a disdrometer. Therefore

335 we examine the flight-level CIP and 2DP data for the convective IOPs in ASCII-12 and ASCII-

336 13. We excluded those IOPs without CIP data (during pre-ASCII), those when the CIP became

337 ice-covered, and those with a higher-than-minimal flight level. That leaves just four "good"

338 convective IOPs.

339 The flight tracks most likely impacted by ground-based seeding are legs 4 and 5, which

340 are over and just downwind of the mountains crest, respectively (Fig. 1). They were flown 1.0

$341 \mathrm{~km}$ AGL (1.2 km AGL) for leg 4 (leg 5). As before (Section 2.2), we separate these tracks in two

342 parts, a region downwind of the AgI generators and a lateral control region (schematic insert map

343 in Fig. 10). The CIP and 2DP measured ice particle concentrations are larger during SEED

344 downwind of the AgI generators compared to NOSEED for these convective cases (Fig. 10a). 
345 The ice crystal concentration is higher only in smaller size bins ( $\mathrm{D}<400 \mu \mathrm{m}, \mathrm{CIP}$ data), but in

346 larger size bins (D>1 mm) both CIP and 2DP data show a lower ice concentration during SEED

347 downwind of the AgI generators (Fig. 10a). Effectively the mean snow particle size decreases by

348 a factor of $\sim$ two during SEED, in convective clouds downwind of the AgI generators. [The

349 NOSEED:SEED mean diameter ratio is 1.44 (2.54) for the CIP (2DP).] A larger ice

350 concentration of smaller ice particles is not observed in the lateral control region (Fig. 10b)

351 during SEED: both CIP and 2DP data indicate no significant change in size distributions from

352 NOSEED to SEED outside the "cone" (Fig. 10b). A similar difference in ice size distribution

353 between target and lateral control sections on legs 4 and 5 is not observed in the seven stratiform 354 cases with suitable data (not shown).

355

356 4. Precipitation impact

$357 \quad 4.1 \quad$ Definition of a double difference parameter

358 Case studies (Pokharel et al., 2014a, b; Pokharel et al., 2015) and model simulations (e.g.,

359 Chu et al., 2014) suggest that the difference in reflectivity vertical structure between NOSEED

360 and SEED is largely due to natural storm variability, even in a rather steady storm. Some of the

361 natural trend can be removed by considering the nearby trend over the same time, in an untreated

362 area. Pokharel et al. (2014a) devise an expression of reflectivity change in the target area,

363 relative to that in a control area. They define the radar reflectivity impact parameter (ZIP) as the

364 difference between the temporal change (SEED - NOSEED) in average reflectivity (in dBZ

365 units) in the target region and that in the control region, i.e.

366

$$
Z I P=\Delta d B Z_{T}-\Delta d B Z_{U}
$$


367 where $\triangle d B Z=d B Z_{S}-d B Z_{N}$, and subscript $\mathrm{S}(\mathrm{N})$ refers to SEED (NOSEED), while subscript

$368 \mathrm{~T}(\mathrm{U})$ refers to treated or target (untreated or control).

370 assume a relationship between $R$ and $Z\left(\mathrm{~mm}^{6} \mathrm{~m}^{-3}\right)$. Pokharel et al. (2014a) define the

371 precipitation impact factor (PIF) as a relative change in $R$ (SEED vs. NOSEED) in the target area

372 compared to the same relative change in the untreated area, i.e.

373

$$
P I F=\frac{\frac{R_{S, T}}{R_{N, T}}}{\frac{R_{S, U}}{R_{N, U}}}
$$

374 Assuming the standard $Z-R$ relationship of the form $R=a Z^{b}$, where $a$ and $b$ are constants, PIF is 375 related to ZIP as follows (Pokharel et al., 2014a):

$$
P I F=10^{\left(\frac{b \times Z I P}{10}\right)}
$$

377 We use the value $b=0.58$ for the WCR (Matrosov, 2007; Pokharel and Vali, 2011) and $b=0.67$

378 for the MRRs and DOW (Matrosov et al., 2009). A ZIP (PIF) value of zero (one) implies the 379 same trend in the target and control areas, i.e. the AgI seeding is neutral.

\subsection{Double difference uncertainties}

There are two uncertainties with this approach. First, a double difference, i.e. the trend in

383 a target area compared to the trend in a control area, only removes the natural trend if reflectivity

384 or precipitation rate are strongly correlated (e.g., Gabriel, 1999). ZIP (as defined in equation 2,

385 with the upwind foothills area as control and the high-mountain region as target) can be

386 interpreted also the change in orographic enhancement from the NOSEED to the SEED period.

387 The correlation between target and control is examined for all NOSEED periods in Part I

388 (Section 6). 
The second uncertainty regards the $Z$ - $R$ relationship, especially for snow. Various studies

390

391

392

393

394 395

396

397

398

399

400

401

402

403

404

405

406

407

408

409

410

411

have shown considerable uncertainty for cm-wave radars (e.g. Fujiyoshi et al., 1990). The

uncertainty is even larger for mm-wave radars when some hydrometeors are large enough to scatter in the Mie regime (>0.6 mm for W-band), as is the case here (Fig. 9) (Matrosov, 2007;

Geerts et al., 2010; Pokharel and Vali, 2011). AgI seeding can change the size distribution of scatterers, e.g. it can result in more numerous small particles yet fewer large ice particles, as is suggested by some flight-level data (Section 3.2). In some scenarios this may increase $R$ yet decrease $Z$. Given this uncertainty, we focus on observed changes in $Z$ rather than radar-derived precipitation rate.

\subsection{Snow gauge analysis}

As part of the Wyoming Weather Modification Pilot Project (WWMPP), surface

precipitation was measured using different types of gauges during ASCII (Breed et al., 2014).

The gauge data were quality-controlled as described in Thériault et al. (2012). The most reliable snow gauges proved to be the ETI (Environmental Technology, Inc.) gauges. Two target sites are averaged for the SM, at Battle Pass and at HY-47 (Highway 47), located $4 \mathrm{~km}$ to the east (Fig. 1). The target site for the MB range is GLEES. All IOPs are listed in the last two columns of Table 1. Snow gauges were deployed upwind of the AgI generators, but these often recorded no measurable or significant snowfall during the IOPs, which are rather short. Therefore a lateral control is assumed for the PIF calculation from gauge data: identical snow gauges were deployed at Elk River and Chimney Park (Fig. 1). These sites are rather far to the south, out of reach of AgI contamination, but still over the respective mountain ranges. Good ETI gauge data, with wind blowing from a suitable direction, are available simultaneously at the control and target 
412 sites for 11 ASCII IOPs (Table 1). These gauge data are partitioned into NOSEED and SEED, to

413 calculate a PIF value for each IOP according to (3).

414

$415 \quad 4.4 \quad$ Seeding impact on radar reflectivity and snowfall

The ZIP (or PIF) can only be calculated for datasets with both target and control

417 measurements. This excludes the Parsivel altogether. For the MRR pair, it excludes select IOPs, 418 i.e. two without upstream control MRR data (Table 1) and three with poor wind direction, such

419 that the AgI plumes likely missed the target MRR at Battle Town site (Fig. 6). For the WCR, it 420 excludes three pre-ASCII flights without leg 1 data, which are used as (upstream) control (Fig.

421 1). The number of remaining IOPs is listed in Table 2 for the various instruments. The ZIP 422 values are calculated for these IOPs, based on average reflectivity from the lowest level AGL to $423500 \mathrm{~m}$ AGL for the WCR, from the lowest level AGL to the highest layer below $1500 \mathrm{~m}$ AGL 424 for the DOW. For the MRR, it is simply the lowest level with uncontaminated data for both 425 probes, representing the layer 0.45-0.60 km AGL. Different instruments have their own target 426 and control regions, SEED/NOSEED times, and different measurement principles, so ZIP values

427 from different probes for the same IOP cannot be expected to be the same. PIF values

428 corresponding to given ZIP values are not shown for the WCR and MRR in Table 2, simply 429 because the $Z-R$ relationship is even more uncertain for shorter-wavelength radars (Section 4.2).

430 The DOW PIF values in Table 2 are computed from instantaneous low-level precipitation

431 estimates. In other words, the DOW radar essentially is a surrogate precipitation gauge:

432 precipitation rate is estimated at grid point resolution for each individual spatially interpolated

433 DOW volume scan and then accumulated over the period of interest, and averaged in the region 434 of interest. This approach is more accurate, since the Z-R relationship is not linear. The upwind 
435 control area for the DOW is based on more IOPs, than the lateral control area, but autocorrelation maps indicate that the latter correlates better with the target region (Section 6 in

437 Part I), therefore results for both control regions are shown in Table 2. instruments indicate an increase in $Z$ (or precipitation rate) in the target region during seeding, 440 compared to the trend in the control region. ZIP values are positive for all but two of the SM 441 cases according to both WCR and DOW data. The DOW-based ZIP/PIF values for the upwind 442 control region are about the same as those for the lateral control region on average, as can be 443 surmised from Fig. 8c-d. The verdict is more divided for the MB range, with positive WCR444 based ZIP values for eight IOPs, negative values for three IOPs, and no effect on the remaining 445 flight. Only one (out of five) and two (out of six) IOPs has a negative gauge-based-PIF over the $446 \mathrm{MB}$ and SM ranges, respectively. In general, the variation in ZIP/PIF values between IOPs is 447 almost as large as its mean value. This uncertainty partly may be attributed to differences in 448 seeding efficacy, related to variables such as cloud temperature and LWP, examined below. 449 There is also a significant measurement uncertainty: the data may not be representative of the 450 true seeding impact. The ZIP estimate includes both a seeding impact and a difference in natural 451 trend between target and control regions. It is impossible to discriminate between these two 452 contributions. Also, aliased sampling (e.g., a precipitation cell may miss a gauge or a WCR 453 transect in one period and traverse it in another) may have a significant effect because the SEED 454 and NOSEED periods are rather short. The DOW radar volume data, collected at rather high 455 time resolution (10 minutes), may be the most representative of the areal mean precipitation rate 456 in the target and control regions. In fact the standard deviation of ZIP/PIF is rather small for the 457 DOW IOPs, at least for the lateral control (Table 2). 
The relative change in precipitation is rather large, ranging from 10-14\% according to the

459 DOW to $57 \%$ for the snow gauges (Table 2). A modelling study of one of the ASCII cases (18

460 Feb 2009) indicates a seeding-induced change of just 10\%, when averaged over a target area

461 comparable to the WCR flight tracks (Chu et al., 2014). The fractional change is large also

462 compared to findings from several randomized seeding experiments, e.g., a 14\% increase for the

463 2005-09 Snowy Precipitation Enhancement Research Project (SPERC) in Australia (Manton and

464 Warren, 2011), and 3-17\% for the 2008-14 WWMPP, depending on the case selection criteria

465 (Rasmussen, 2014). The large fractional change may be related to the rather light precipitation in

466 ASCII IOPs, $R<1 \mathrm{~mm} \mathrm{~h}^{-1}$ on average (Table 2). Also shown in Table 2 is the expected change in

467 precipitation rate $(\Delta R)$ based on the PIF estimate, i.e.

468

$\Delta R=R(P I F-1)$

469 The average $\Delta R$ listed in Table 2 is based on values for each individual IOP, not the average PIF

470 for all IOPs. $\Delta R$ ranges between $0.05-0.5 \mathrm{~mm} \mathrm{~h}^{-1}$, depending on instrument, which is a little

471 smaller than the SPERC. ( $\Delta R$ is larger for the gauge data, because of an outlier PIF estimate over

472 the MB range.) So while the fractional change in snowfall is high for the ASCII cases, compared

473 to randomized seeding experiments, the absolute change is not because of ASCII's focus on light

474 orographic precipitation.

475

$476 \quad 4.5 \quad$ Profiles of ZIP

477

The impact of ground-based seeding is expected to remain within the turbulent PBL,

478 which is $0.5-0.8 \mathrm{~km}$ deep in most ASCII IOPs, according to WCR vertical velocity spectra

479 (Geerts et al., 2011, 2013). Deeper mixing may occur when convection is present over the target

480 region. But the (mostly shallow) convective cells observed in ASCII tend to naturally precipitate 
481 mostly in the lee of the mountain (Jing and Geerts, 2015), and thus the seeding effect may be felt 482 mostly further downwind than leg 5 or Battle Town site, the location of the target MRR (Fig. 1).

483 The target region for the DOW does extend further in the lee (Jing et al., 2015). In short, the 484 attribution of positive ZIP values to AgI seeding is more likely if these positive values are 485 concentrated in the lowest $\sim 1 \mathrm{~km}$ AGL. ZIP estimates become less reliable with height because 486 there are fewer echoes aloft (e.g., "data presence” lines in Fig. 2).

Profiles of ZIP for the three radar systems are shown in Fig. 11. The average ZIP profile, 488 based on all available IOPs, does show positive values in the lowest $1 \mathrm{~km}$, and near-zero values 489 aloft for the WCR (green line in Fig. 11c). Positive values decrease with height also for the 490 DOW, at least up to $2 \mathrm{~km}$, above which level the data density becomes sparse and the ZIP 491 estimate is dominated by a fewer cases (Fig. 11d). The profile of MRR composite ZIP (Fig. 11d) 492 also shows decreasing values with height, but these values are all negative above $1 \mathrm{~km}$ AGL. Of 493 the three composite ZIP lines in Fig. 11d, the MRR line is the least "informed", since it is based 494 on the fewest cases and on 1D data only, with some uncertainty about the location of the AgI 495 plume relative to the downstream MRR site (Section 2.5).

497 peaks near the surface for stratiform clouds and peaks higher (just below $1 \mathrm{~km}$ AGL) for 498 convective clouds (Fig. 11a). This is consistent with the shallower mixing of AgI nuclei in 499 stratiform clouds, and for convective precipitation to be lofted more, with positive ZIP values 500 mostly in the lee (Jing and Geerts, 2015). Stratification by fetch from the AgI generators (Fig. 501 11b) shows higher ZIP values near the surface at close fetch and over a greater depth at greater 502 fetch. Here close fetch means 2.5 and $7.5 \mathrm{~km}$, if the wind is normal to WCR legs 2 and 3 503 respectively, and the greater fetch refers to normal distances of 13 and $18 \mathrm{~km}$ to legs 4 and 5 
504

505

506

507

508

509

510

511

512

513

514

515

516

517

518

519

520 521 radars.

522

523

524

525

526

respectively. Finally, stratification by mountain range shows a similar lapse of ZIP values with height over both mountains (Fig. 11c), but higher values over the SM, where sampled clouds tend to be warmer and have more supercooled liquid water (SLW) (see Part I).

\subsection{Ambient and cloud conditions affecting precipitation impact}

The ZIP (PIF) values for the three radar systems and for the ETI gauges are plotted against cloud and environmental parameters, to examine whether these parameters have a measurable impact on seeding efficacy (Fig. 12). Each symbol corresponds to one IOP; different symbols are used for different data sources. Whereas the DOW and MRR PIF profiles shown in Fig. 11d are derived from average $\mathrm{Z}$ values using Eqn (4) (resulting in the unique relation between ZIP and PIF in Fig. 11d), DOW and MRR PIF values in Fig. 12 are computed from instantaneous, local low-level precipitation estimates, as in Table 2. Such approach is not meaningful for the WCR, since it is an airborne (moving) measurement, and thus no local time integral can be taken. Instead, WCR reflectivity values are averaged first (in Z units) over the flight legs covering the appropriate region and time for any IOP, and then ZIP and PIF are computed from Eqns (2) and (4) respectively. The PIF scale on the right ordinate of each panel does not apply to the WCR, due to different ZIP-PIF relationships for mm-wave and cm-wave

Lateral and upwind control values are shown separately for the DOW. The key parameter is cloud base temperature, as temperature controls AgI-induced ice nucleation in cloud. A cloud temperature significantly above about $-7^{\circ} \mathrm{C}$ may render $\mathrm{AgI}$ seeding ineffective, as the $\mathrm{AgI}$ activation (measured as the number of crystals yielded per gram of AgI) increases by 2.5 orders of magnitude between -6 and $-10^{\circ} \mathrm{C}$ (DeMott, 1997). But, as mentioned in the Introduction, 
527 seeding efficacy is constrained also at lower temperatures, $\sim-20^{\circ} \mathrm{C}$, depending on the

528 concentration of natural ice nuclei. The ASCII IOPs do not reveal a significant relationship

529 between ZIP/PIF and cloud base (LCL) temperature (Fig. 12a). ZIP/PIF values tend to be highest

530 between -7 to $-15^{\circ} \mathrm{C}$, but the average PIF for warmer cases (cloud base temperature $>-7^{\circ} \mathrm{C}$ is

531 almost the same as that for colder cases. This may indicate that in most cases air parcels rise well

532 above the LCL.

533 Deep orographic clouds with very cold cloud tops (below -25 to $-30^{\circ} \mathrm{C}$ ) are not conducive

534 to seeding because of ice initiation aloft and the seeder-feeder effect at lower levels (Manton and

535 Warren, 2011; Manton et al., 2011; Grant and Elliott, 1974). Indeed ZIP 0 (PIF 1) for IOPs

536 with a cloud top temperature below $-25^{\circ} \mathrm{C}$ (Fig. 12d), and PIF is larger for IOPs with a cloud top

537 temperature above $-25^{\circ} \mathrm{C}$, compared to cold cloud tops. Deeper clouds also tend to have smaller

538 PIF (Fig. 12f), while PIF values are overwhelmingly large for shallow-cloud IOPs (cloud depth <

$539 \quad 3.0 \mathrm{~km})$, which dominate in ASCII.

540 The main driver for ice crystal growth and thus seeding efficacy is SLW content (Ryan et

541 al., 1976), which tends to increase with temperature (Super and Heimbach, 2005). We do not

542 find a clear relationship between ZIP/PIF and the liquid water path (LWP) (Fig. 12c), which is

543 surprising. Maybe ASCII does not include enough cases with high LWP values.

544 The relative impact of seeding on precipitation rate is inversely proportional to the

545 natural precipitation intensity in stratiform orographic clouds, according to modelling work (Xue

546 et al., 2013). The reason is that ice crystals are naturally more abundant and SLW is consumed

547 more efficiently in deeper, more intense storms. ASCII observations tend to confirm this,

548 although the correlation is weak (Fig. 12e). Finally, stronger cross-mountain wind tends to

549 produce more SLW and thus more efficient seeding. But with fresh snow on the ground, surface 
550 winds exceeding $\sim 10 \mathrm{~m} \mathrm{~s}^{-1}$ may produce blowing snow, which may serve as a natural ice crystal

551 source from the ground up (Geerts et al., 2015b), overwhelming the effect of ground-based AgI

552 seeding. In general, there is no significant relation between ZIP/PIF and wind speed (Fig. 12b).

553 None of the relationships shown in Fig. 12 are statistically significant at the $\mathrm{p}=0.05$ level.

554 ASCII measurements are inadequate to gain insights into how key cloud and environmental

555 parameters impact seeding efficacy. This may be because the relationship between relative

556 precipitation change and these parameters is complex, and controlled by other factors such as

557 natural ice nucleus concentration, which we did not measure. It also reflects the uncertainty in

558 ZIP/PIF estimation (Section 4.2).

559

560 5. Discussion

561

The data collected in ASCII allow a unique, in-depth exploration of precipitation changes

562 in response to ground-based AgI seeding. Before summarizing the findings, we raise several

563 caveats and suggestions for any future observational studies into glaciogenic cloud seeding:

564 - The biggest challenge remains natural variability (National Research Council, 2003;

565 Garstang et al., 2005), thus the experimental design should include control regions or

566 periods. These need to be representative, with strongly correlated precipitation records (e.g.

567 simultaneous measurements laterally displaced over the same mountain range) yet

568 uncontaminated. Each storm is different, and to address both the wide space of parameters

569 (e.g. temperature, LWP, drop size distribution, cloud depth, wind speed) and the aliasing

570 inherent to relatively brief sampling in individual storms, numerous cases are needed for

571 physical process studies. This statement is separate from any statistical argument about

572 number of cases needed for randomized experiments. 
573 - Caution is warranted in relating radar reflectivity changes to precipitation changes. This

574 study does not address how Z-R relations can change in response to seeding, due to changes

575 in particle size distribution and/or particle density. Direct in situ or remote measurements of

$576 \quad$ ice water content and snow density are desirable.

577 - This study also ignored variations in concentrations of natural cloud-active aerosol in the

578 upstream airmass. Both cloud condensation nuclei and especially ice nuclei should be

579 measured.

580 - Freshly fallen snow at the target ground site should be chemically analyzed for trace

581 elements including Ag and other co-varying minerals, as was done in ASCII-12 but not in

582 other ASCII campaigns. This is because it offers the only confirmation that the falling snow

583 is impacted by seeding. The more frequently falling snow can be sampled, the better. This

584 may require a large sampling surface under light snowfall. The sampling should continue

585 about two hours after the AgI generator switch-off time to examine delayed impact.

586

- One of the challenges in windy cases is that snow particles measured near the surface may

587 originate from the ground or nearby trees. We placed the in situ instruments on a scaffold a

588 few meters above the snow surface in a tree-sheltered opening at Battle Town site. At the

589 same time, they cannot be placed too high, since some instruments, like the hotplate and

590 disdrometer, become unreliable under strong winds.

591

- The surface target site needs to be selected carefully, perhaps with the aid of detailed flow

592 modelling over the target mountain. Battle Town site is more likely to be impacted by

593 upwind ground-based seeding because of its location near a pass into which flow is

594 channeled, especially under more stable conditions. On the other hand, GLEES is located

595 behind the bulge of MB Peak situated on top of the MB plateau. GLEES is less suitable as 
stratified flow (and seeding-impacted snow) may be diverted around this bulge, whereas the

597 air over that location often arises from aloft due to frequent downslope windstorms in the lee

598 of MB Peak which rapidly sublimate snow (e.g., Geerts et al., 2015a).

599 - The analysis of the impact of ground-based seeding is complicated by boundary-layer

600 turbulence, ice crystal transfer from the ground up into cloud (Geerts et al., 2015b), and

601 complex flow patterns around the terrain. Also, airborne cloud and precipitation probes are of

602 limited use to examine ground-based seeding because the minimum flight level is rather high

603 in cloud over complex terrain. Much progress can be made examining cloud microphysical

604 processes following the airborne injection of AgI nuclei, preferably in stratiform orographic

605 clouds. This has been done before (e.g., Deshler et al., 1990), but not with novel cloud radar

606 and in situ cloud probes.

607

608 5. Conclusions

609

This paper examines the impact of ground-based AgI seeding on snow growth in

610 orographic clouds observed in southern Wyoming during ASCII. Reflectivity profiles were

611 collected both upstream (control) and downstream (target) of the AgI generators from three radar

612 systems, two profiling (WCR and MRR), and one volume-scanning (DOW). The impact of AgI

613 seeding is isolated by contrasting the measurements collected before seeding commenced

614 (NOSEED) against those during seeding (SEED), both in a target region and in a control region.

615 Each period is about two hours long, and is adjusted for advection depending on the location of

616 the target relative to the AgI generators. The three radar systems and snow gauges are

617 complementary in that they have their own target and control regions, measurement technique,

618 vantage, and IOP array in the composite. 
Data from all IOPs were included in the composite analysis, unless a significant change

620 in weather occurred between NOSEED and SEED, the relevant instrument did not work, or the

621 wind direction was wrong. For ASCII-12, a higher-than-expected Ag concentration in fresh snow

622 samples collected at the target site (Battle Town site) during SEED was used also as an argument

623 for effective targeting and inclusion of a dataset in the composite analysis.

624 The ASCII sample size is relatively small, with 21 IOPs for the WCR, 10 for the DOW, 6

625 for the MRR pair, and 11 for the snow gauges. Thus natural trends from NOSEED to SEED

626 persist in the composite, e.g. storms naturally weakened during most of the ASCII-12 IOPs over

627 the SM, but they tended to intensify from NOSEED to SEED in the IOPs over the MB. An

628 attempt is made to remove the natural trend in each IOP by comparing the trend in the target

629 region to that in the nearby control region. Thus double differences or double ratios are

630 examined, such as the PIF, involving both a geographical and a temporal change. This reduces

631 but does not remove uncertainties in attribution to AgI seeding.

632 The following conclusions emerge:

633 - All instruments indicate an increase in near-surface radar reflectivity (precipitation rate for

634 gauges) in the target region during seeding, compared to the trend in the control region. The

635 change is most pronounced at low levels, consistent with ground-based seeding. In relative

636 terms, the increase is rather large, but this double difference/ratio (ZIP/PIF) varies

637 significantly from IOP to IOP.

638 - Most of this variation relates to non-homogenous natural trends across the mountain range,

639 and/or to unrepresentativeness of the measurements and the control region. In other words,

640 signal detection in a noisy field such as precipitation remains the main challenge. 
- The ASCII sample size is not adequate either to quantify the magnitude of the seeding impact on snowfall with confidence, or to identify the atmospheric and cloud conditions most suitable for ground-based seeding. The strongest signal is that clouds with warmer tops (>$25^{\circ} \mathrm{C}$ ) are more suitable for glaciogenic seeding.

- More numerous, but smaller ice crystals are observed in convective clouds downwind of the AgI generators at flight level ( 1.1 km AGL) during SEED, compared to NOSEED. This change is not observed to the side of AgI plumes (lateral control region) in the same convective IOPs, nor in stratiform clouds. A Parsivel disdrometer located at the target site does not show such increase in ice crystal concentration during SEED.

- PIF values are larger for IOPs over the Sierra Madre compared to the IOPs over the Medicine Bow. This may be attributable to a higher cloud LWP and temperature over the former range, and/or to local topographic factors that control the flow to the target site.

- The ASCII project leaves room for improvements. Several suggestions are made to improve the experimental design of future cloud seeding research campaigns.

Acknowledgements: The ASCII campaign is funded by the National Science Foundation grant AGS-1058426. This work also received funding from the Wyoming Water Development Commission grant 1001552C and the United States Geological Survey grant 10000628S, under the auspices of the University of Wyoming Water Research Program. The operation of the AgI generators, the upstream MRR, and the microwave radiometer was supported by the WWMPP, which is funded by the State of Wyoming and managed by Barry Lawrence. We thank the crews of the UWKA and the DOW for working under often harsh conditions, Dan Breed for the MRR 
663 data collected at Ladder Livestock ranch, and Arlen Huggins for the trace analysis of snow 664 samples collected at Battle Pass. 


\section{References}

Breed, D., Rasmussen, R., Weeks, C., Boe, B., Deshler, T., 2013. Evaluating winter orographic cloud seeding: Design of the Wyoming Weather Modification Pilot Project (WWMPP). J. Appl. Meteor. Climatol., 53, 282-299.

Chu, X., Xue, L., Geerts, B., Rasmussen. R., Breed, D., 2014. A case study of radar observations and WRF LES simulations of the impact of ground-based glaciogenic seeding on orographic clouds and precipitation: Part I: Observations and model validations. J. Appl. Meteor. Climat., 53, 2264-2286.

DeMott, P. J., 1997. Report to North Dakota Atmospheric Resource Board and Weather Modification Incorporated on Tests of the Ice Nucleating Ability of Aerosols Produced by the Lohse Airborne Generator, Dept. Atmos. Sci., Colorado State Univ., Report, Fort Collins, CO, 15 pp.

Deshler, T., Reynolds, D. W., Huggins, A. W., 1990. Physical response of winter orographic clouds over the Sierra Nevada to airborne seeding using dry ice or silver iodide. J. Appl. Meteor., 29, 288-330.

Fujiyoshi, Y., Endoh, T., Yamada, T., Tsuboki, K., Tachibana, Y., Wakahama, G., 1990.

Determination of a Z-R Relationship for snowfall using a radar and high sensitivity snow gauges. J. Appl. Meteor., 29, 147-152.

Gabriel, K. R., 1999. Ratio statistics for randomized experiments in precipitation stimulation. J. Appl. Meteor., 38, 290-301.

Garstang, M., Bruintjes, R., Serafin, R., Orville, H., Boe, B., Cotton, W., Warburton, J., 2005. Finding common ground. Bull. Amer. Meteor. Soc., 86, 647-655. 
Geerts, B., Miao, Q., Yang, Y., Rasmussen, R., Breed, D., 2010. An airborne profiling radar study of the impact of glaciogenic cloud seeding on snowfall from winter orographic clouds. J. Atmos. Sci., 67, 3286-3301.

Geerts, B., Pokharel, B., Kristovich, D.A.R., 2015b. Blowing snow as a natural glaciogenic cloud seeding mechanism. Mon. Wea. Rev.., 143, 5017-5033.

Geerts, B., Yang, Y., Rasmussen, R., Haimov, S., Pokharel, B., 2015a. Snow growth and transport patterns in orographic storms as estimated from airborne vertical-plane dualDoppler radar data. Mon. Wea. Rev., 143, 644-665.

Grant, L. O., Elliott, R. E., 1974. The cloud seeding temperature window. J. Appl. Meteor., 13, $355-363$.

Holroyd, E. W., McPartland, J. T., Super, A.B., 1988. Observation of silver iodide plumes over the Grand Mesa of Colorado. J. Appl. Meteor., 27, 1125-1144.

Houze, R. A., 2012. Orographic effects on precipitating clouds. Rev. Geophys., 50, RG1001. http://dx.doi.org/10.1029/2011RG000365.

Huggins, A. W., 2007. Another wintertime cloud seeding case study with strong evidence of seeding effects. J. Weather Mod., 39, 9-36.

Jing, X., Geerts, B., Friedrich, K., Pokharel, B., 2015. Dual-polarization radar data analysis of the impact of ground-based glaciogenic seeding on winter orographic clouds. Part I: mostly stratiform clouds. J. Appl. Meteor. Climatol., 54, 1944-1969.

Jing, X., Geerts, B., 2015. Dual-polarization radar data analysis of the impact of ground-based glaciogenic seeding on winter orographic clouds. Part II: convective clouds J. Appl. Meteor. Climat., 54, 2099-2117. 
Maahn, M., Kollias, P., 2012. Improved Micro Rain Radar snow measurements using Doppler spectra post-processing. Atmos. Meas. Tech., 5, 2661-2673.

Manton, M. J., Warren, L., Kenyon, S. L., Peace, A. D., Bilish, S. P., Kemsley, K., 2011. A confirmatory snowfall enhancement project in the Snowy Mountains of Australia. Part I: Design and response variables. J. Appl. Meteor. Climatol., 50, 1432-1447.

Manton, M. J., Warren, L., 2011. A confirmatory snowfall enhancement project in the Snowy Mountains of Australia. Part II: Primary and associated analyses. J. Appl. Meteor. Climatol., 50, 1448-1458.

Matrosov, S. Y., 2007. Modeling backscatter properties of snowfall at millimeter wavelengths. J. Atmos. Sci., 64, 1727-1736.

Matrosov, S. Y., Campbell, C., Kingsmill, D., Sukovich, E., 2009. Assessing snowfall rates from X-band radar reflectivity measurements. J. Atmos. Oceanic Technol., 26, 2324-2339.

National Research Council, 2003. Critical Issues in Weather Modification Research. National Academy Press, 123 pp.

Pokharel, B., Vali, G., 2011. Evaluation of collocated measurements of radar reflectivity and particle sizes in ice clouds. J. Appl. Meteor. Climatol., 50, 2104-2119.

Pokharel, B., Geerts, B., Jing, X., 2014a. The impact of ground-based glaciogenic seeding on orographic clouds and precipitation: a multi-sensor case study. J. Appl. Meteor. Climatol., $53,890-909$.

Pokharel, B., Geerts, B., Jing, X., Friedrich, K., Aikins, J., Breed, D., Rasmussen, R., Huggins, A., 2014b. The impact of ground-based glaciogenic seeding on orographic clouds and precipitation: a multi-sensor case study. Atmos. Res., 147-148, 162-181. 
731

732

733

734

735

736

737

738

739

740

741

742

743

744

745

746

747

748

749

750

751

752

753

Pokharel, B., Geerts, B., Jing, X., 2015. The impact of ground-based glaciogenic seeding on clouds and precipitation over mountains: a case study of shallow orographic cloud with large supercooled droplets. J. Geophys. Res., 120, 6056-6079.

Pokharel, B., Geerts B., 2016. A multi-sensor study of the impact of ground-based glaciogenic seeding on clouds and precipitation over mountains in Wyoming. Part I: Project description. Atmos. Res., accepted. DOI: 10.1016/j.atmosres.2016.08.008.

Rasmussen, R., 2014: The Wyoming Weather Modification Pilot Project, Level II Study. Executive Summary. Available at http://wwdc.state.wy.us/weathermod/WYWeatherModPilotProgramExecSummary.pdf

Ryan, B. F., Wishart, E. R., Shaw, D. E., 1976. The growth rates and densities of ice crystals between $-3^{\circ} \mathrm{C}$ and $-21^{\circ} \mathrm{C}$. J. Atmos. Sci., 33, 842-850.

Super, A. B., Heimbach, J.A., 2005. Feasibility of snowpack enhancement from Colorado winter mountain clouds: Emphasis on supercooled liquid water and seeding with silver iodide and propane. Final Report, Technical Services Center, Bureau of Reclamation, Denver Federal Center, Denver, CO, 63 pp.

Thériault, J., Rasmussen, R., Ikeda K., and Landolt, S., 2012. Dependence of snow gauge collection efficiency on snowflake characteristics. J. Appl. Meteor. Climatol., 51, 745762.

Xue, L., Tessendorf, S., Nelson, E., Rasmussen, R., Breed, D., Parkinson, Holbrook, S., P., Blestrud, D., 2013. AgI cloud seeding effects as seen in WRF simulations. Part II: 3D real case simulations and sensitivity tests. J. Appl. Meteor. Climatol., 52, 1458-1476.

Xue, L., Chu, X., Rasmussen, R., Breed, D., Boe, B., Geerts, B., 2014. The dispersion of silver iodide particles from ground-based generators over complex 
terrain. Part II: WRF Large-Eddy simulations vs. Observations. J. Appl. Meteor.

755 Climatol., 53, 1342-1361.

756 Yuter, S., Houze, R. A., 1995. Three-dimensional kinematic and microphysical evolution of 757 Florida cumulonimbus. Part II: Frequency distributions of vertical velocity, reflectivity, 758 and differential reflectivity. Mon. Wea. Rev., 123, 1941-1963. 


\section{$759 \quad$ List of Tables}

760 Table 1: ASCII IOPs for which data from the MRR pair, the Parsivel disdrometer, and/or the 761 gauges can be used in the seeding impact analysis, based on the wind direction and silver 762 concentration in snow. Also shown are the NOSEED and SEED periods for these instruments. 763 The last column lists the IOPs that can be used for DOW-based seeding impact analysis.

Table 2: Average reflectivity impact parameter (ZIP) and precipitation impact factor PIF (mean 766 and standard deviation) for all available IOPs, based on different probes. $R$ is the average liquid 767 equivalent precipitation rate during NOSEED. $\triangle R$ is the average change in precipitation rate 768 based on the PIF estimate. The variability between IOPs is highlighted by stating the mean \pm the 769 standard deviation. 


\section{List of Figures}

Fig. 1: Terrain map and ASCII deployment map over the Sierra Madre (SM) and Medicine Bow (MB) Mountains in southern Wyoming. The solid black lines show the fixed UWKA flight tracks and square symbols show the ground-based AgI generators. The three most commonly used AgI generators are shown by the filled squares.

Fig. 2: Normalized frequency-by-altitude displays of WCR reflectivity for 21 flights, i.e. nine in ASCII-12 over the SM, and eight in ASCII-13 plus four in pre-ASCII, both over the MB. The right panels apply to the four tracks downwind of the AgI generators (target), the left panels to leg 1 upstream of the generators (control) (Fig. 1). The top panels apply to the NOSEED period, the middle panels to the SEED period, and the bottom panels show the difference (SEED NOSEED). The sample size for the upper four FADs is expressed in terms of UWKA flight distance (one sample per $\sim 4 \mathrm{~m}$ ). The dotted lines in the upper four FADs are the $10^{\text {th }}, 25^{\text {th }}, 75^{\text {th }}$, and $90^{\text {th }}$ percentiles. Also shown are the mean reflectivity profiles (orange lines in the upper four panels, and black lines in the bottom panels) and the "data presence", i.e. the percentage of WCR range gates with a WCR echo as a function of height (white line in the upper four panels). The precipitation rate $(R)$ shown in the upper abscissa of the bottom panels is inferred from $R=0.39$ $Z^{0.58}$.

Fig. 3: WCR reflectivity difference (SEED minus NOSEED) FADs for the target legs (2-5) for all three-generators IOPs (20 flights) a) within the assumed AgI dispersion cones (shown schematically as green track portions in the insert map) and b) outside this region. The insert maps also show the location of the three AgI generators (blue asterisks), the wind direction (arrow), and the sample size $(\mathrm{km})$. The orientation of the cones varies with the mean wind direction for each IOP.

Fig. 4: WCR reflectivity difference (SEED minus NOSEED) FADs for the 12 flights over the MB (left panels) and for the nine flights over the SM (right panels). The target region is shown in the upper panels, the control region in the lower panels. The solid and dotted lines show the average values during SEED and NOSEED, respectively. 
Fig. 5: WCR reflectivity difference (SEED minus NOSEED) FADs for six convective cloud IOPs (left panels) and for 15 stratiform cloud IOPs (right panels), for the target region (upper panels) and the control region (lower panels).

Fig. 6: Silver (Ag) concentration difference in snow samples (SEED minus NOSEED) as a function of the nearest distance between the estimate AgI plume center and the snow collection site (Battle Town site). The asterisks show the three-generators IOPs, and the crosses show the eight-generator IOPs.

Fig. 7: MRR reflectivity difference (SEED minus NOSEED) FADs for a) the downstream MRR (target) and b) the upstream MRR (control), for six ASCII-12 cases (Table 1). The sample size applies to both MRR sites.

Fig. 8: Upper panels: Height (km AGL) of the lowest unblocked DOW beam above the terrain of the SM. Also shown are the control and target regions for (a) all eight AgI generators and (b) the three core generators, for a given wind direction. Lower panels: DOW reflectivity difference FADs (SEED - NOSEED) for (a) the upwind control region (10 IOPs), (b) the lateral control region (subset of 5 IOPs), and (c) the target region (10 IOPs). Also shown in these panels are the mean reflectivity profiles during NOSEED and SEED.

Fig. 9: Normalized frequency-by-diameter display (FDD) of snow particle concentration measured by a Parsivel disdrometer at Battle Town site during (a) NOSEED and (b) SEED, composited for eight ASCII-12 IOPs (Table 1). Panel (c) shows the difference (SEED minus NOSEED). The solid yellow lines in (a) and (b) show the average value; these lines are repeated as black lines in (c).

Fig. 10: Ice particle size distribution measured by the CIP (red) and the 2DP (blue) at flight level during SEED (solid) and NOSEED (dotted) along legs 4 and 5. The data come from the four convective IOPs with tracks at the minimum flight level; a) within the assumed AgI dispersion region (shown as green flight sections in the insert schematic map) and b) outside this region. This region varies with the mean wind direction for each IOP. 
832 Fig. 11: Vertical profiles of WCR ZIP and PIF, based on composites of 21 flights partitioned in 833 two parts, as follows: a) convective vs stratiform IOPs, b) short fetch (legs 2-3) vs long fetch 834 (legs 4-5) target region, and c) MB vs SM. Panel (d) shows the ZIP and PIF profiles based on 835 composite reflectivity for all available IOPs over the SM, according to data from three different 836 radars.

837

838 Fig. 12: Variation of reflectivity impact parameter (ZIP) and precipitation impact factor (PIF) 839 with ambient and cloud conditions, based on four instrument types (three radar and one gauge), 840 each with their own target and control region(s), and each with their own largely overlapping but 841 not identical SEED/NOSEED periods and available IOPs, located over the MB (blue) or the SM 842 (red) ranges. The horizontal dashed line in all panels separates a positive effect (above) from a 843 negative effect (below). The ZIP values are related to a) cloud base temperature, b) low-level 844 mean wind speed, c) liquid water path, d) cloud top temperature, e) precipitation rate, and f) 845 cloud depth. The vertical dotted lines separate different regimes. The mean PIF values for those 846 regimes, based on all instruments/IOPs, are shown. 
Tables

Table 1: ASCII IOPs for which data from the MRR pair, the Parsivel disdrometer, and/or the gauges can be used in the seeding impact analysis, based on the wind direction and silver concentration in snow. Also shown are the NOSEED and SEED periods for these instruments. The last column lists the IOPs that can be used for DOW-based seeding impact analysis.

\begin{tabular}{|c|c|c|c|c|c|c|c|c|c|c|c|}
\hline \multirow[t]{2}{*}{ range } & \multirow{2}{*}{$\begin{array}{c}\text { IOP date } \\
\text { (YYYYMMDD) }\end{array}$} & \multicolumn{2}{|c|}{$\begin{array}{c}\text { NOSEED } \\
\text { UTC (HHMM) }\end{array}$} & \multicolumn{2}{|c|}{$\begin{array}{c}\text { SEED } \\
\text { UTC (HHMM) }\end{array}$} & \multicolumn{2}{|c|}{ MRR } & \multirow{2}{*}{\begin{tabular}{|c} 
Parsivel \\
target
\end{tabular}} & \multicolumn{2}{|c|}{ snow gauge } & \multirow[t]{2}{*}{ DOW } \\
\hline & & start & stop & start & stop & target & control & & target & control & \\
\hline \multirow{11}{*}{ 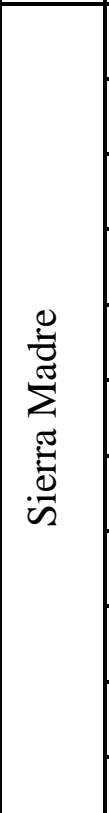 } & 20120118 & 0000 & 0145 & 0146 & 0346 & $\mathrm{Y}$ & $\mathrm{N}$ & $\mathrm{Y}$ & $\mathrm{N}$ & $\mathrm{N}$ & $\mathrm{N}$ \\
\hline & 20120119 & 1623 & 1826 & 1827 & 2030 & $\bar{Y}$ & $\bar{N}$ & $\bar{Y}$ & $\bar{Y}$ & $\mathrm{~N}$ & $\bar{Y}$ \\
\hline & 20120211 & 0213 & 0518 & 0519 & 0824 & $\mathrm{Y}$ & $\mathrm{Y}$ & $\mathrm{Y}$ & $\mathrm{Y}$ & $\mathrm{Y}$ & $\bar{Y}$ \\
\hline & 20120212 & & & & & & & & & & $\mathrm{Y}$ \\
\hline & 20120213 & 1900 & 2100 & 2101 & 2300 & $\bar{Y}$ & $\bar{N}$ & $\bar{Y}$ & $\bar{Y}$ & $\bar{Y}$ & $\bar{Y}$ \\
\hline & 20120221 & 1918 & 2139 & 2140 & 2538 & $\mathrm{Y}$ & $\mathrm{Y}$ & $\mathrm{Y}$ & $\mathrm{Y}$ & $\mathrm{Y}$ & $\bar{Y}$ \\
\hline & 20120222 & 1327 & 1527 & 1528 & 1728 & $\bar{Y}$ & $\mathrm{Y}$ & $\mathrm{Y}$ & $\mathrm{Y}$ & $\bar{Y}$ & $\bar{Y}$ \\
\hline & $20120228 \mathrm{a}$ & 1331 & 1527 & 1528 & 1724 & $\mathrm{Y}$ & $\mathrm{Y}$ & $\mathrm{Y}$ & $\mathrm{Y}$ & $\mathrm{Y}$ & $\mathrm{Y}$ \\
\hline & $20120228 b$ & & & & & & & & & & $\bar{Y}$ \\
\hline & 20120229 & & & & & & & & & & $\bar{Y}$ \\
\hline & 20120303 & 1730 & 1956 & 1957 & 2223 & $\mathrm{Y}$ & $\mathrm{Y}$ & $\mathrm{Y}$ & $\mathrm{Y}$ & $\mathrm{Y}$ & $\mathrm{Y}$ \\
\hline \multirow{5}{*}{ 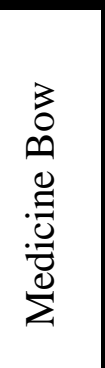 } & 20130129 & 2159 & 2359 & 2400 & 2600 & & & & Y & Y & \\
\hline & 20130201 & 1830 & 2030 & 2031 & 2231 & & & & $\mathrm{Y}$ & $\mathrm{Y}$ & \\
\hline & 20130228 & 0000 & 0210 & 0211 & 0425 & & & & $\mathrm{Y}$ & $\bar{Y}$ & \\
\hline & 20090218 & 1630 & 1830 & 1831 & 2031 & & & & $\mathrm{Y}$ & $\bar{Y}$ & \\
\hline & 20090325 & 1515 & 1715 & 1716 & 1931 & & & & $\mathrm{Y}$ & $\mathrm{Y}$ & \\
\hline
\end{tabular}


Table 2: Average reflectivity impact parameter (ZIP) and precipitation impact factor PIF (mean and standard deviation) for all available IOPs, based on different probes. $R$ is the average liquid equivalent precipitation rate during NOSEED. $\Delta R$ is the average change in precipitation rate based on the PIF estimate. The variability between IOPs is highlighted by stating the mean \pm the standard deviation.

\begin{tabular}{|c|c|c|c|c|c|c|c|}
\hline \multirow{2}{*}{ instrument } & \multirow{2}{*}{$\begin{array}{l}\text { control } \\
\text { region }\end{array}$} & \multirow{2}{*}{$\begin{array}{c}\text { mountain } \\
\text { range }\end{array}$} & \multirow{2}{*}{$\begin{array}{l}\text { \# of } \\
\text { IOPs }\end{array}$} & \multirow{2}{*}{$\mathrm{ZIP}(\mathrm{dB})$} & \multirow{2}{*}{ PIF } & $\mathbf{R}$ & \multirow{2}{*}{$\frac{\Delta \mathbf{R}}{\left(\mathbf{m m ~ h}^{-1}\right)}$} \\
\hline & & & & & & $\left(\mathrm{mm} \mathrm{h}^{-1}\right)$ & \\
\hline \multirow{3}{*}{ WCR } & \multirow{3}{*}{ upwind } & $\begin{array}{c}\text { both } \\
\text { ranges }\end{array}$ & 21 & $1.76 \pm 5.25$ & & & \\
\hline & & SM & 9 & $3.29 \pm 6.46$ & & & \\
\hline & & MB & 12 & $0.62 \pm 3.72$ & & & \\
\hline MRR & upwind & SM & 6 & $1.1 \pm 8.2$ & & & \\
\hline \multirow{2}{*}{ DOW } & upwind & SM & 10 & $0.92 \pm 2.73$ & $1.14 \pm 0.32$ & 0.47 & 0.07 \\
\hline & lateral & SM & 5 & $0.91 \pm 0.74$ & $1.10 \pm 0.09$ & 0.57 & 0.05 \\
\hline \multirow{3}{*}{$\begin{array}{l}\text { precipitation } \\
\text { gauges }\end{array}$} & \multirow{3}{*}{ lateral } & $\begin{array}{l}\text { both } \\
\text { ranges }\end{array}$ & 11 & & $1.57 \pm 1.01$ & 0.58 & 0.33 \\
\hline & & SM & 6 & & $1.73 \pm 1.02$ & 0.64 & 0.47 \\
\hline & & MB & 5 & & $1.38 \pm 1.09$ & 0.53 & 0.20 \\
\hline
\end{tabular}




\section{Figures}

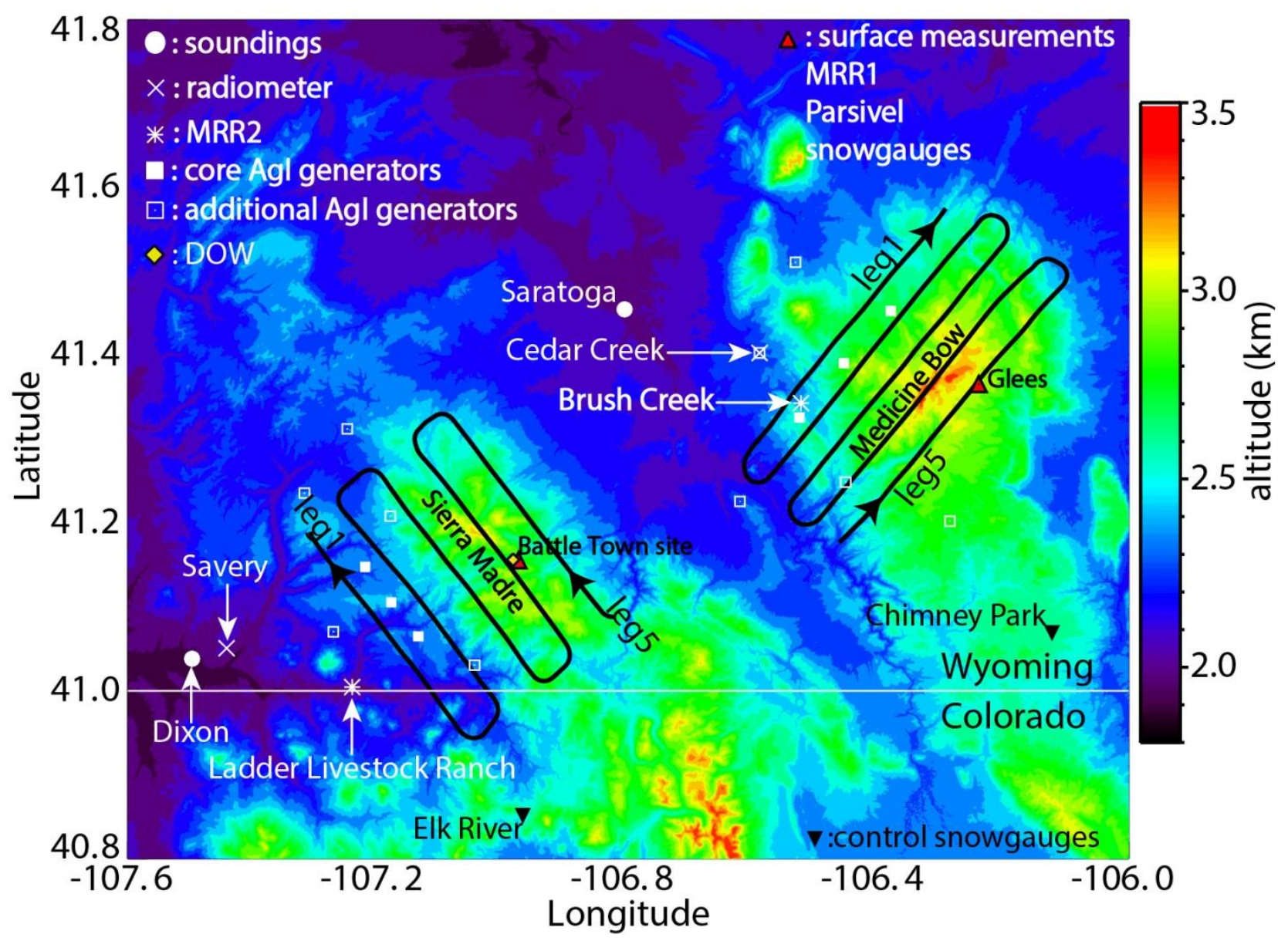

Fig. 1: Terrain map and ASCII deployment map over the Sierra Madre (SM) and Medicine Bow (MB) Mountains in southern Wyoming. The solid black lines show the fixed UWKA flight tracks and square symbols show the ground-based AgI generators. The three most commonly used AgI generators are shown by the filled squares. 

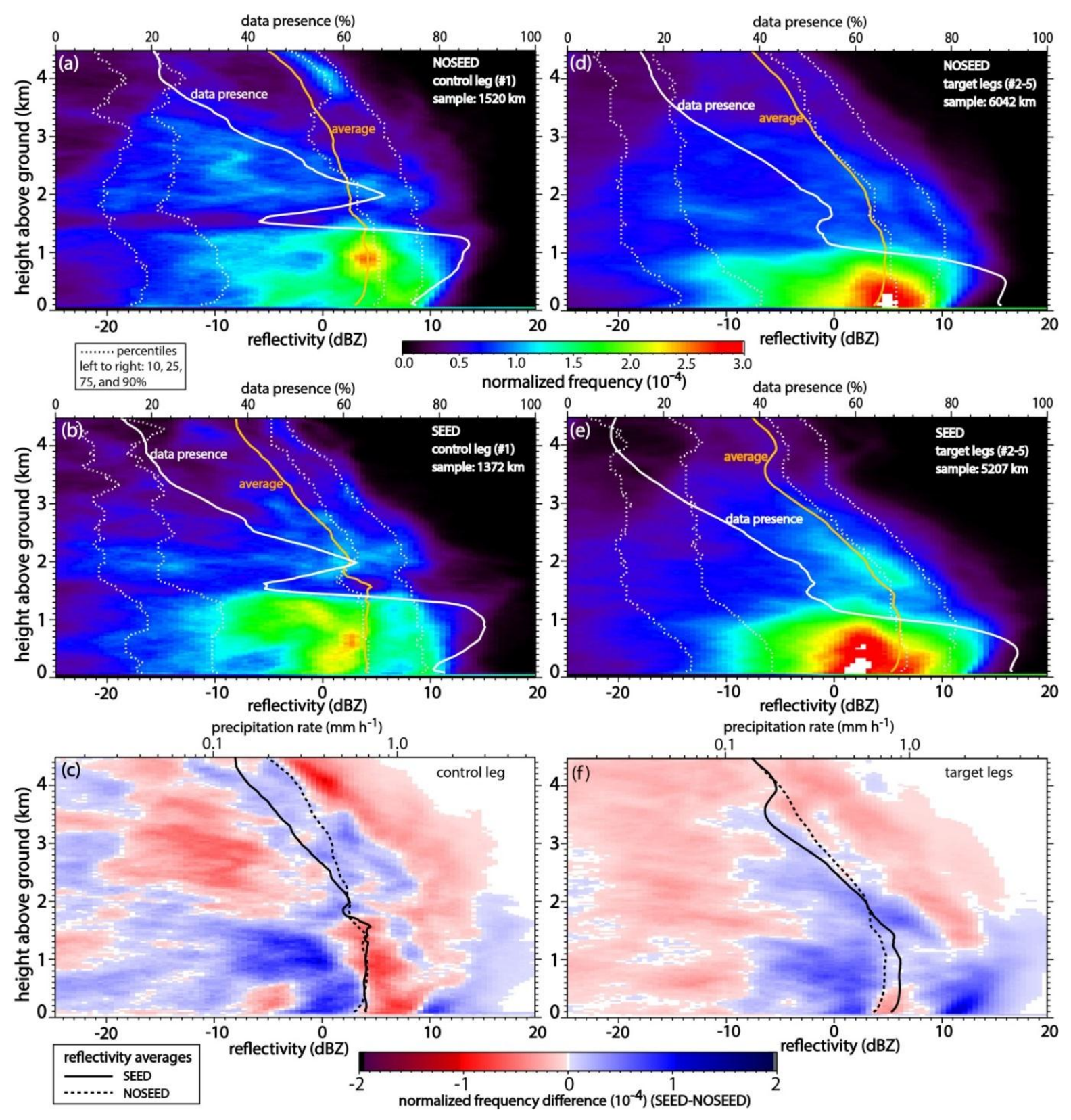

Fig. 2: Normalized frequency-by-altitude displays of WCR reflectivity for 21 flights, i.e. nine in ASCII-12 over the SM, and eight in ASCII-13 plus four in pre-ASCII, both over the MB. The right panels apply to the four tracks downwind of the AgI generators (target), the left panels to leg 1 upstream of the generators (control) (Fig. 1). The top panels apply to the NOSEED period, the middle panels to the SEED period, and the bottom panels show the difference (SEED NOSEED). The sample size for the upper four FADs is expressed in terms of UWKA flight distance (one sample per $\sim 4 \mathrm{~m}$ ). The dotted lines in the upper four FADs are the $10^{\text {th }}, 25^{\text {th }}, 75^{\text {th }}$, and $90^{\text {th }}$ percentiles. Also shown are the mean reflectivity profiles (orange lines in the upper four panels, and black lines in the bottom panels) and the "data presence", i.e. the percentage of WCR range gates with a WCR echo as a function of height (white line in the upper four panels). The precipitation rate $(R)$ shown in the upper abscissa of the bottom panels is inferred from $R=0.39$ $Z^{0.58}$ 

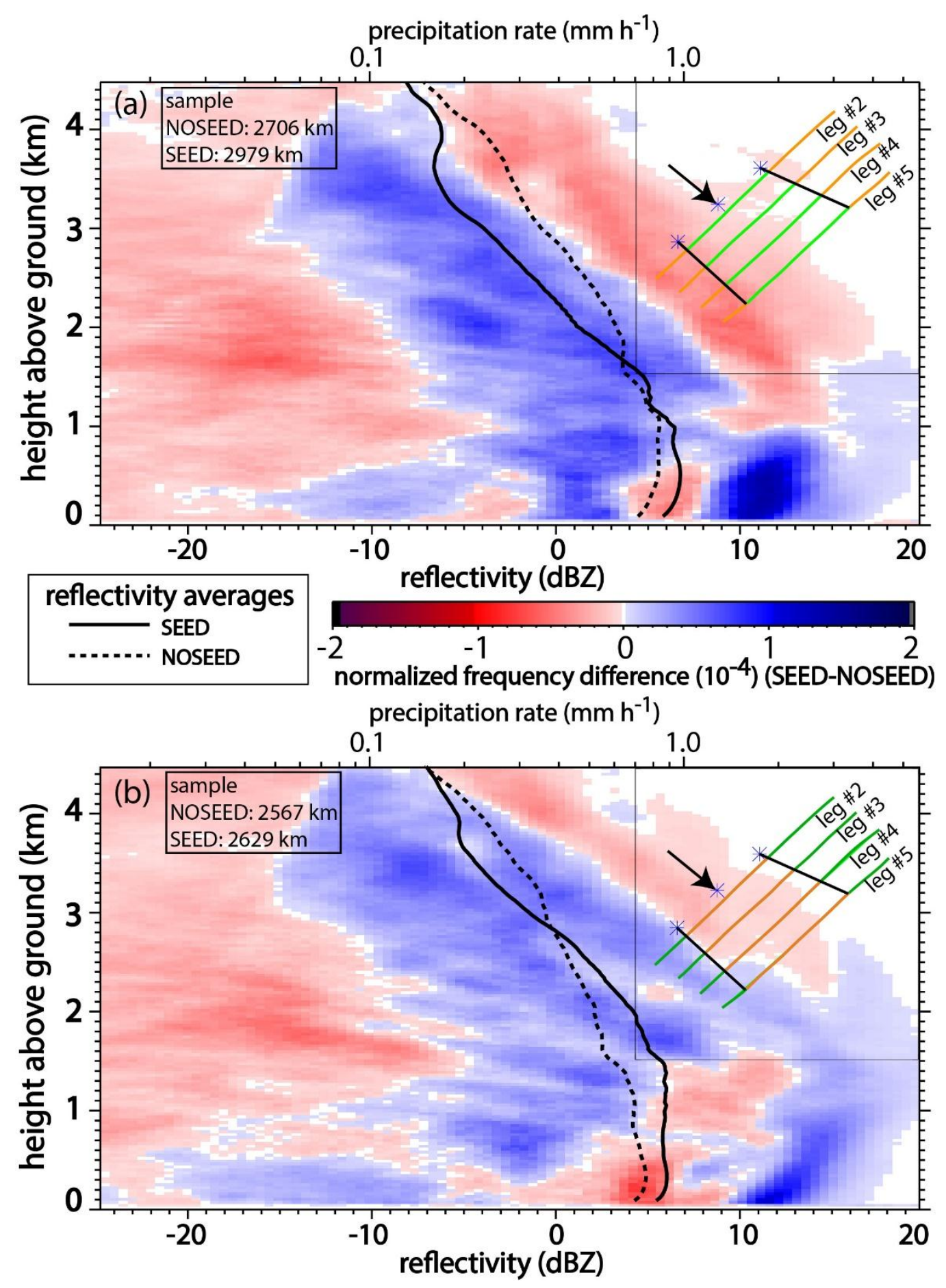

Fig. 3: WCR reflectivity difference (SEED minus NOSEED) FADs for the target legs (2-5) for all three-generators IOPs (20 flights) a) within the assumed AgI dispersion cones (shown schematically as green track portions in the insert map) and b) outside this region. The insert maps also show the location of the three AgI generators (blue asterisks), the wind direction (arrow), and the sample size $(\mathrm{km})$. The orientation of the cones varies with the mean wind direction for each IOP. 


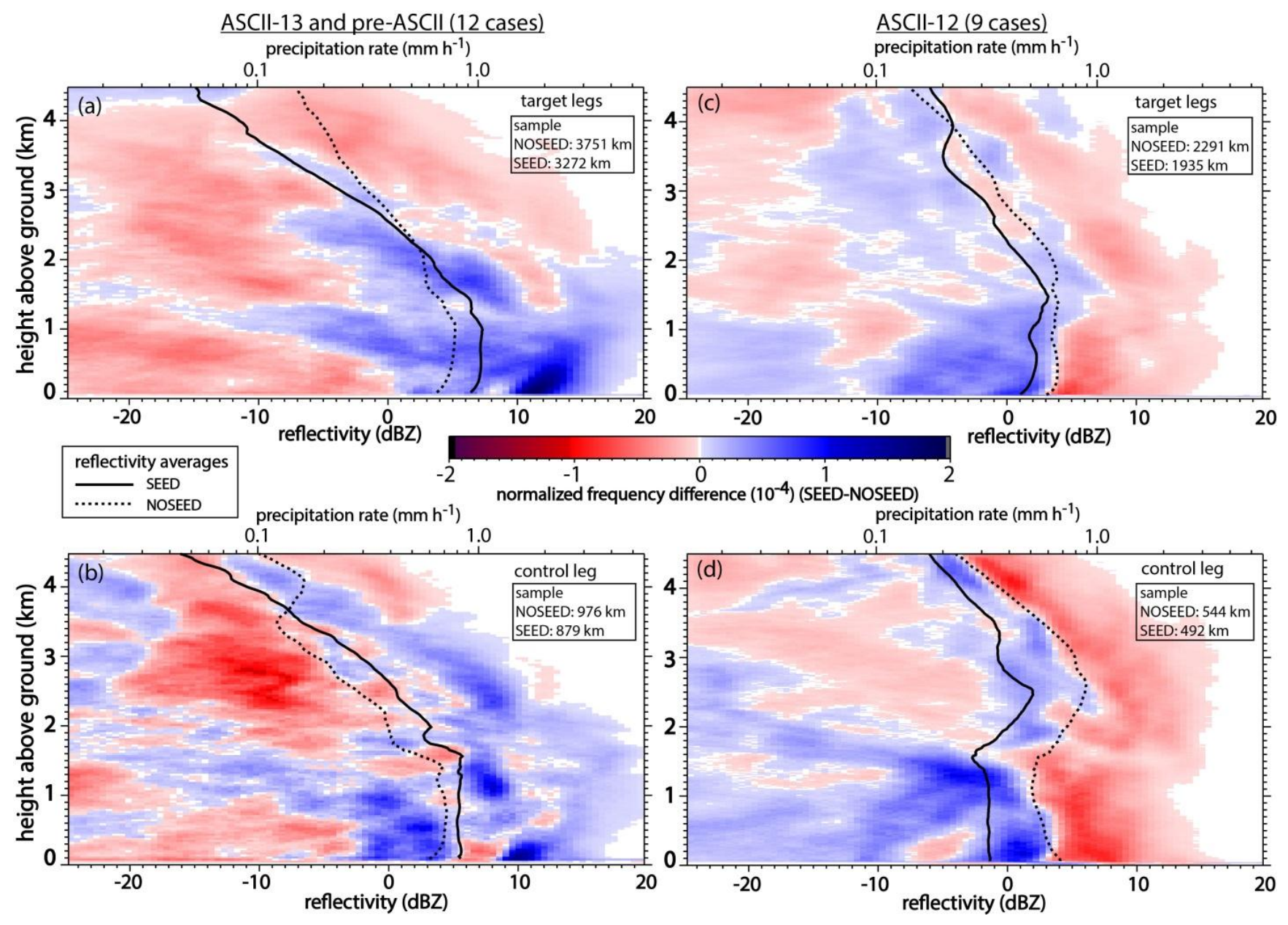

Fig. 4: WCR reflectivity difference (SEED minus NOSEED) FADs for the 12 flights over the MB (left panels) and for the nine flights over the SM (right panels). The target region is shown in the upper panels, the control region in the lower panels. The solid and dotted lines show the average values during SEED and NOSEED, respectively. 

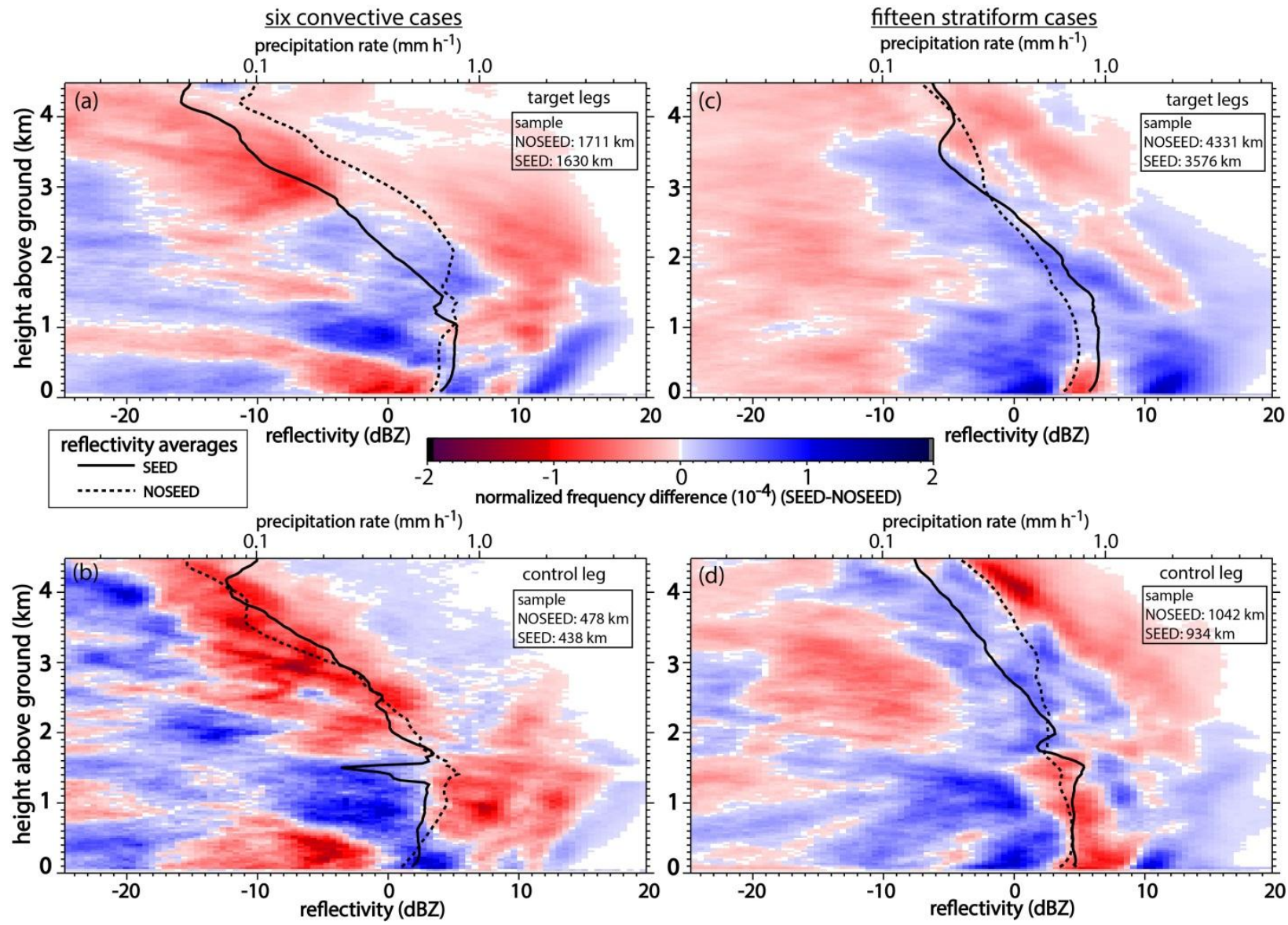

Fig. 5: WCR reflectivity difference (SEED minus NOSEED) FADs for six convective cloud IOPs (left panels) and for 15 stratiform cloud IOPs (right panels), for the target region (upper panels) and the control region (lower panels). 


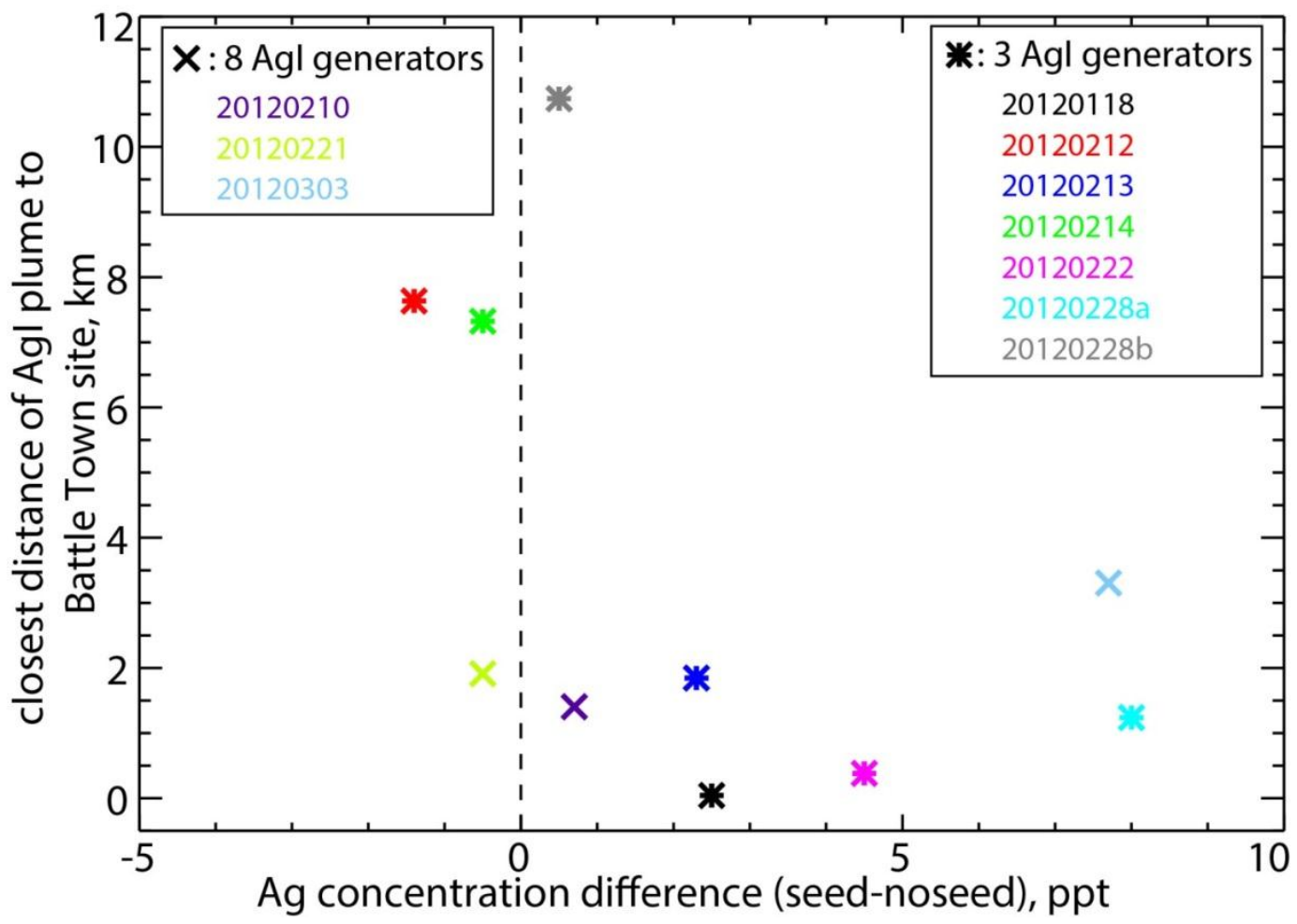

Fig. 6: Silver (Ag) concentration difference in snow samples (SEED minus NOSEED) as a function of the nearest distance between the estimate AgI plume center and the snow collection site (Battle Town site). The asterisks show the three-generators IOPs, and the crosses show the eight-generator IOPs. 

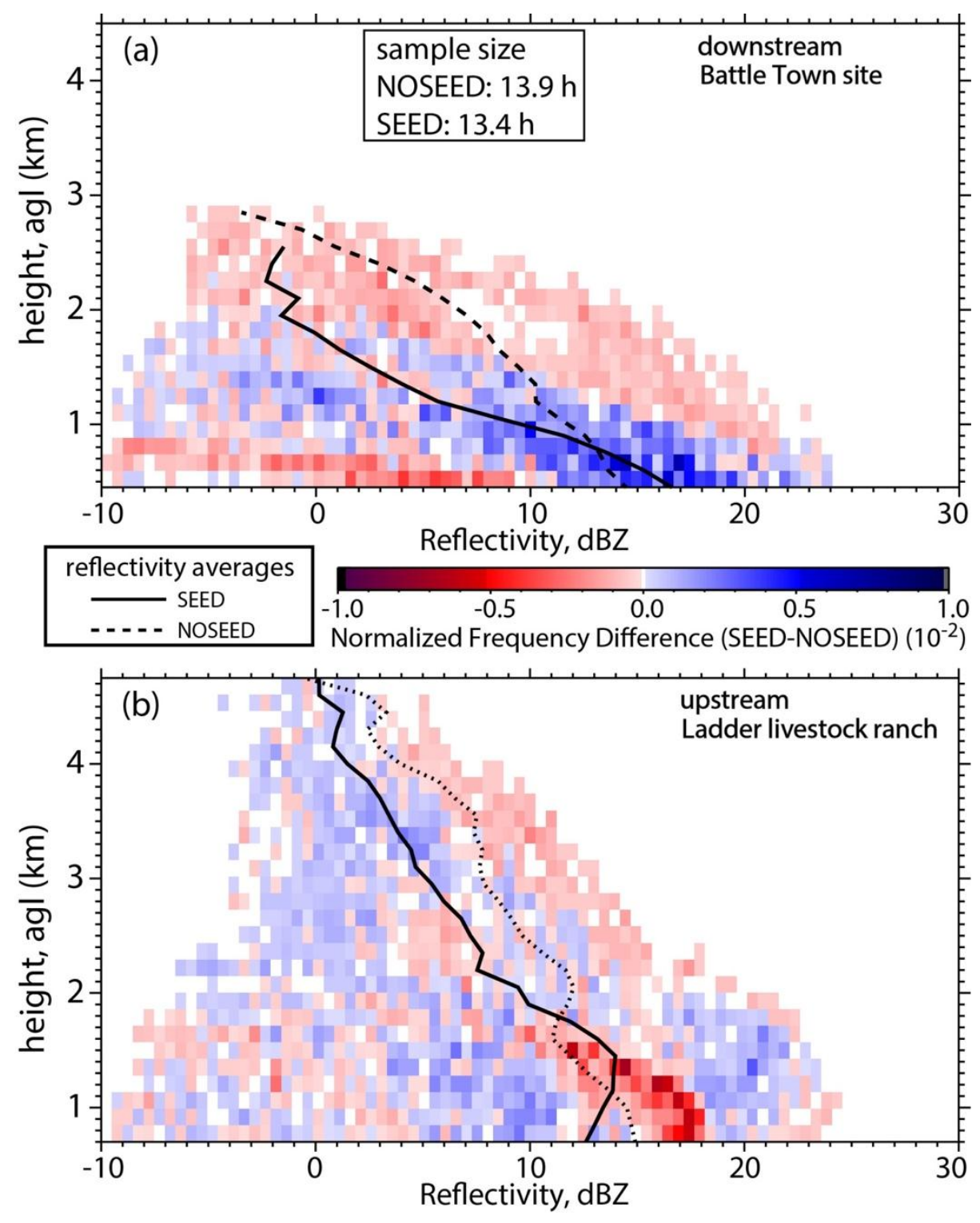

Fig. 7: MRR reflectivity difference (SEED minus NOSEED) FADs for a) the downstream MRR (target) and b) the upstream MRR (control), for six ASCII-12 cases (Table 1). The sample size applies to both MRR sites. 

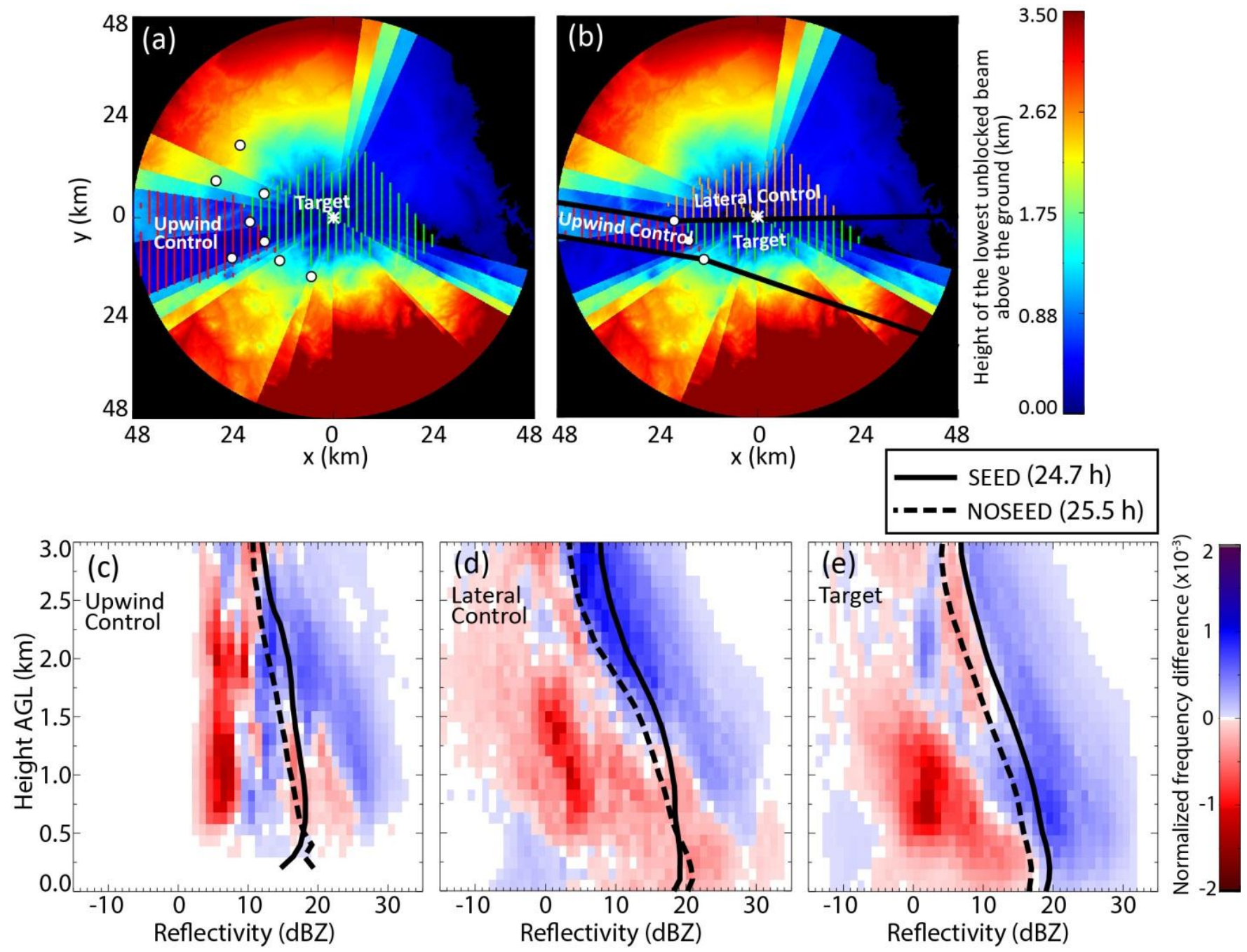

Fig. 8: Upper panels: Height (km AGL) of the lowest unblocked DOW beam above the terrain of the SM. Also shown are the control and target regions for (a) all eight AgI generators and (b) the three core generators, for a given wind direction. Lower panels: DOW reflectivity difference FADs (SEED - NOSEED) for (a) the upwind control region (10 IOPs), (b) the lateral control region (subset of 5 IOPs), and (c) the target region (10 IOPs). Also shown in these panels are the mean reflectivity profiles during NOSEED and SEED. 

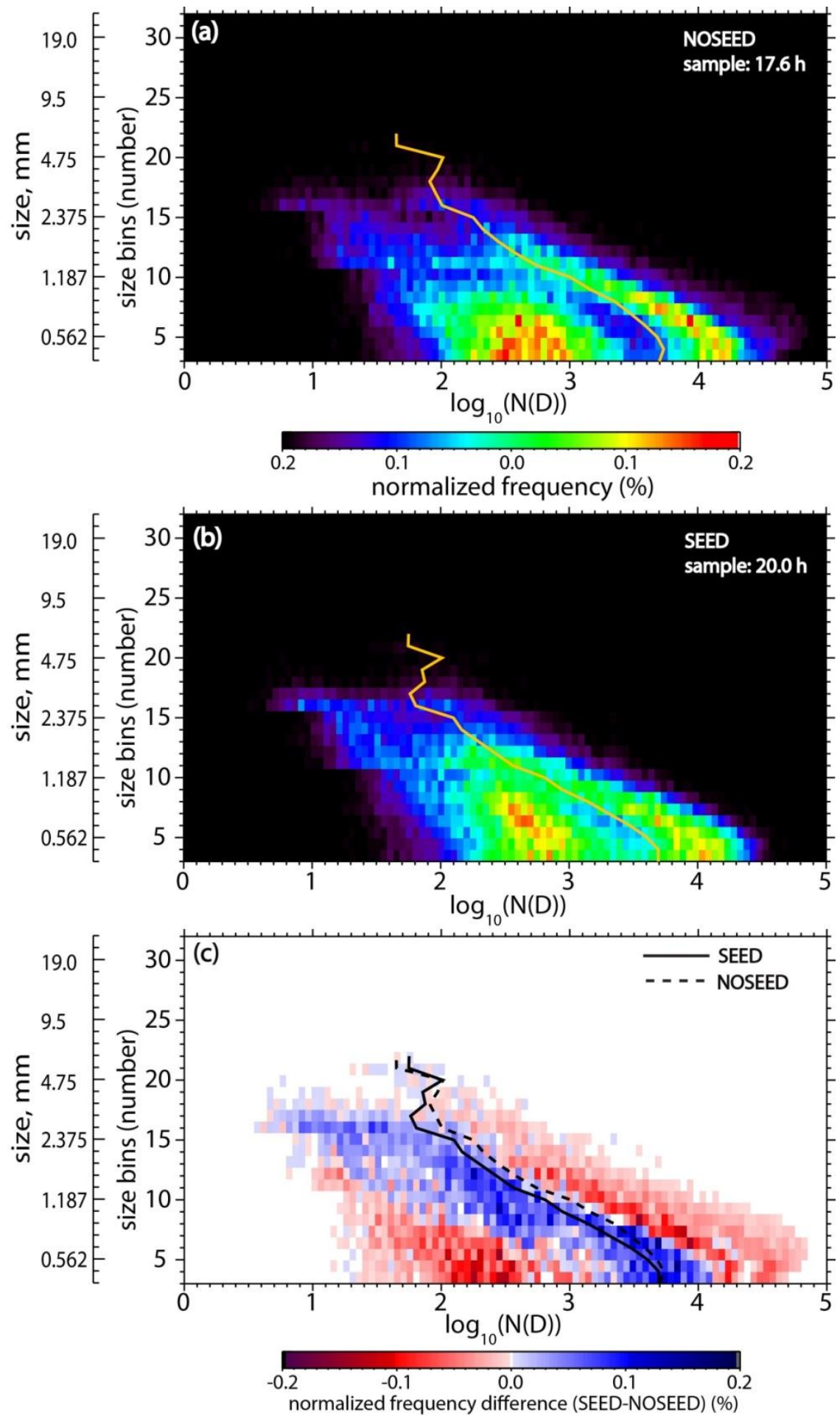

Fig. 9: Normalized frequency-by-diameter display (FDD) of snow particle concentration measured by a Parsivel disdrometer at Battle Town site during (a) NOSEED and (b) SEED, composited for eight ASCII-12 IOPs (Table 1). Panel (c) shows the difference (SEED minus NOSEED). The solid yellow lines in (a) and (b) show the average value; these lines are repeated as black lines in (c). 

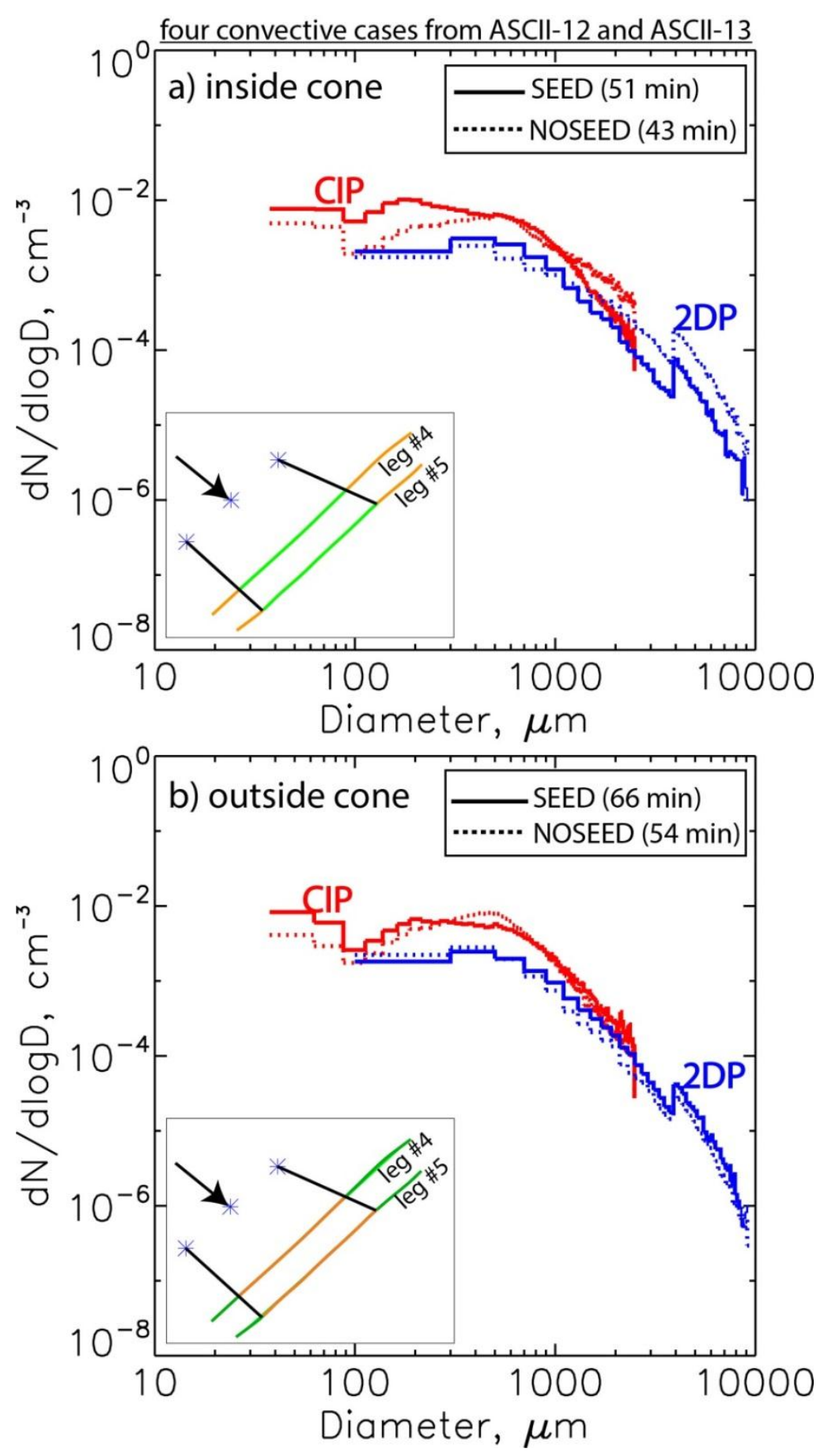

Fig. 10: Ice particle size distribution measured by the CIP (red) and the 2DP (blue) at flight level during SEED (solid) and NOSEED (dotted) along legs 4 and 5. The data come from the four convective IOPs with tracks at the minimum flight level; a) within the assumed AgI dispersion region (shown as green flight sections in the insert schematic map) and b) outside this region. This region varies with the mean wind direction for each IOP. 

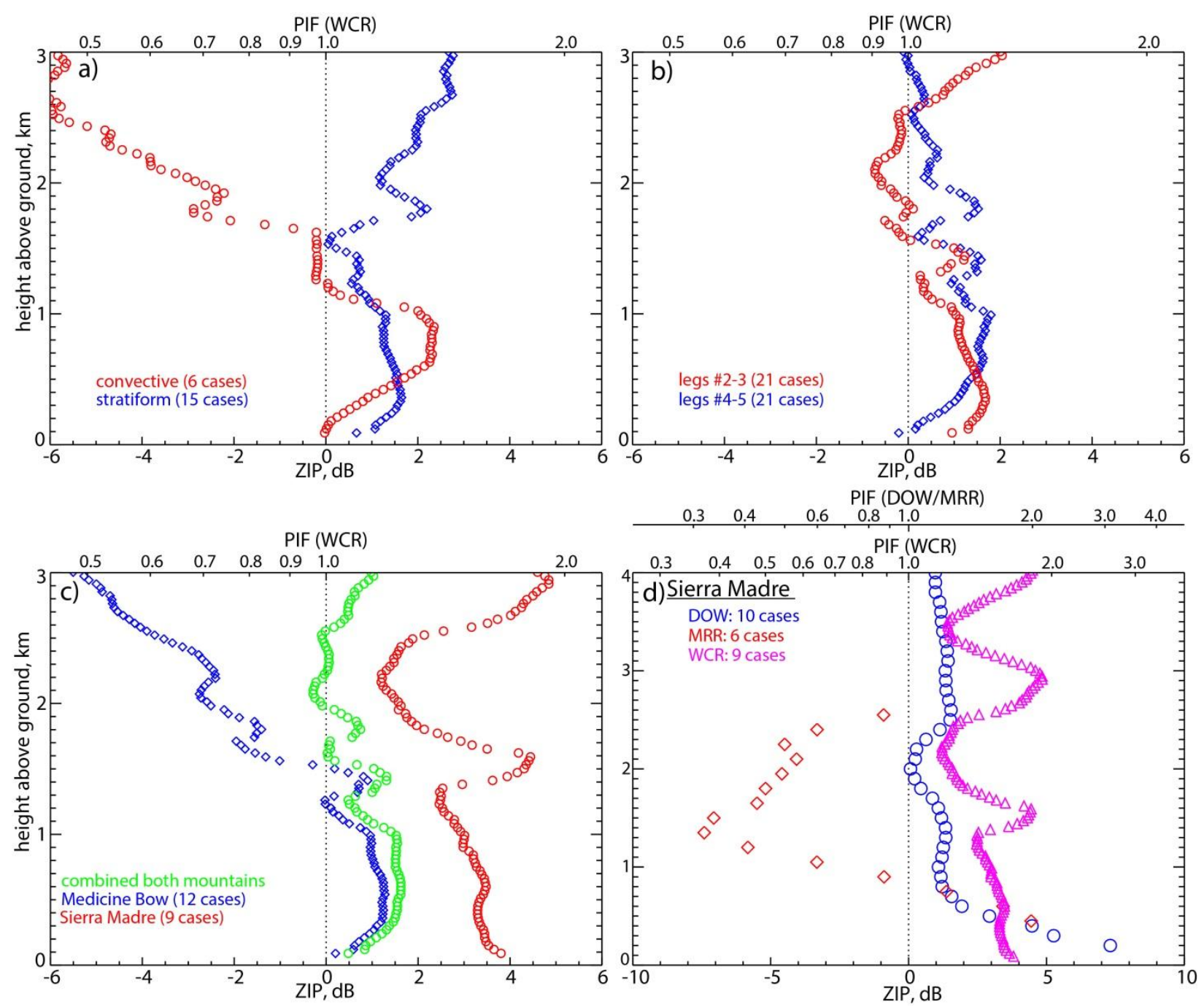

Fig. 11: Vertical profiles of WCR ZIP and PIF, based on composites of 21 flights partitioned in two parts, as follows: a) convective vs stratiform IOPs, b) short fetch (legs 2-3) vs long fetch (legs 4-5) target region, and c) MB vs SM. Panel (d) shows the ZIP and PIF profiles based on composite reflectivity for all available IOPs over the SM, according to data from three different radars. 

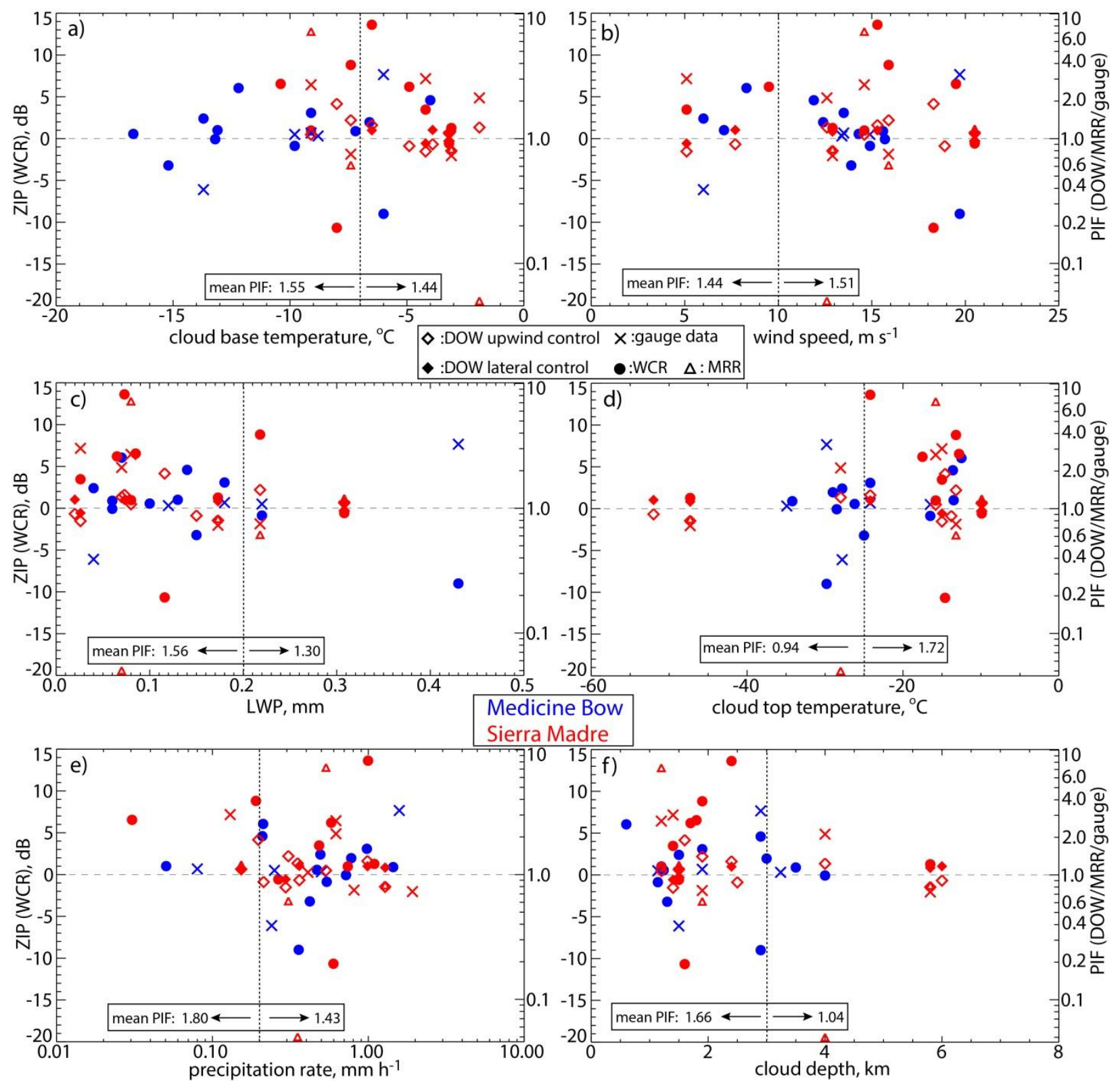

Fig. 12: Variation of reflectivity impact parameter (ZIP) and precipitation impact factor (PIF) with ambient and cloud conditions, based on four instrument types (three radar and one gauge), each with their own target and control region(s), and each with their own largely overlapping but not identical SEED/NOSEED periods and available IOPs, located over the MB (blue) or the SM (red) ranges. The horizontal dashed line in all panels separates a positive effect (above) from a negative effect (below). The ZIP values are related to a) cloud base temperature, b) low-level mean wind speed, c) liquid water path, d) cloud top temperature, e) precipitation rate, and f) cloud depth. The vertical dotted lines separate different regimes. The mean PIF values for those regimes, based on all instruments/IOPs, are shown. 